IZA DP No. 10337

Personality and Mental Health: The Role and Substitution Effect of Emotional Stability and Conscientiousness

Caroline Wehner

Trudie Schils

Lex Borghans

October 2016 


\title{
Personality and Mental Health: The Role and Substitution Effect of Emotional Stability and Conscientiousness
}

\author{
Caroline Wehner \\ IZA und Maastricht University \\ Trudie Schils \\ Maastricht University \\ Lex Borghans \\ Maastricht University and IZA
}

Discussion Paper No. 10337

October 2016

\author{
IZA \\ P.O. Box 7240 \\ 53072 Bonn \\ Germany \\ Phone: +49-228-3894-0 \\ Fax: +49-228-3894-180 \\ E-mail: iza@iza.org
}

Any opinions expressed here are those of the author(s) and not those of IZA. Research published in this series may include views on policy, but the institute itself takes no institutional policy positions. The IZA research network is committed to the IZA Guiding Principles of Research Integrity.

The Institute for the Study of Labor (IZA) in Bonn is a local and virtual international research center and a place of communication between science, politics and business. IZA is an independent nonprofit organization supported by Deutsche Post Foundation. The center is associated with the University of Bonn and offers a stimulating research environment through its international network, workshops and conferences, data service, project support, research visits and doctoral program. IZA engages in (i) original and internationally competitive research in all fields of labor economics, (ii) development of policy concepts, and (iii) dissemination of research results and concepts to the interested public.

IZA Discussion Papers often represent preliminary work and are circulated to encourage discussion. Citation of such a paper should account for its provisional character. A revised version may be available directly from the author. 


\section{ABSTRACT \\ Personality and Mental Health: The Role and Substitution Effect of Emotional Stability and Conscientiousness ${ }^{*}$}

A growing number of economic studies show that low emotional stability is typically negatively related to socioeconomic outcomes, while conscientiousness predicts desirable results. However, possible mechanisms behind these relations are far less explored. Gaining insights into the mechanisms is important, because this knowledge is crucial to develop preand intervention programs. We address this research gap by analyzing the relation between low emotional stability and mental ill-health as well as the possible substitution effect of conscientiousness both theoretically and empirically. Using the British Cohort Study, we find that low emotional stability at ages 10 and 16 significantly predicts mental ill-health at ages $16,26,30,34$ and 42 and that more conscientiousness significantly mitigates the negative relation between low emotional stability and mental health. Our results suggest that particularly both low emotionally stable and low conscientious individuals are more likely to experience mental ill-health related to a reduced problem-solving ability.

JEL Classification: D03, I12, I14, I18, I24

Keywords: mental health, personality differences, health inequality, child development, socioeconomic disadvantage

Corresponding author:

Caroline Wehner

IZA

Schaumburg-Lippe-Str. 5-9

53072 Bonn

Germany

E-mail: wehner@iza.org

\footnotetext{
* We would like to thank Christopher Boyce, Arnaud Chevalier, Deborah Cobb-Clark, Bart Golsteyn, Peter Kuhn, Oliver Lüdtke, David Neumark, Milena Nikolova, Brent W. Roberts and Ulf Zölitz for their valuable comments. We further presented the article at the conference "Economics, Health and Happiness" in Lugano, at the "2016 LEAD Retreat" at University Tübingen, at the "19"t IZA European Summer School in Labor Economics", at the "2016 Stirling PhD Conference in Behavioral Science" as well as at Maastricht University where we received helpful input from the participants. In addition, we thank Richard Forsythe for editorial suggestions. This research did not receive any specific grant from funding agencies in the public, commercial, or not-for-profit sectors.
} 


\section{INTRODUCTION}

\section{Introduction}

A rapidly growing number of economic studies use personality traits to predict various socioeconomic outcomes and show that low emotional stability is typically negatively related to education, labor market and mental health outcomes, while conscientiousness is almost seen as a guarantor for desirable results (Cuijpers et al. (2010), Almlund et al. (2011), Fletcher (2013), Golsteyn and Schils (2014), Mendolia and Walker (2014)). However, possible mechanisms behind these relations are far less explored. Nevertheless, gaining insights into the mechanisms would be important, because this knowledge is crucial to develop effective and efficient pre- and intervention programs. We address this research gap by analyzing the relation between low emotional stability and mental ill-health as well as the possible substitution effect of conscientiousness 1 .

Our approach is twofold: on the one hand, we investigate the psychological literature and put the insights gained into an economic framework; and on the other hand, we analyze the relation between personality and mental health empirically, using personality at ages 10 and 16 and mental health outcomes at ages 16, 26, 30, 34 and 42 . We use the British Cohort Study, which allows following people from birth up until the age of 42 , with information about personality and a measure for mental health in adolescence and adulthood.

The empirical analysis shows that low emotional stability at age 16 significantly predicts mental ill-health in both adolescence and adulthood. Accordingly, an increase in emotional stability by 1 standard deviation in adolescence is related to a decrease in mental health problems by between 0.08 and 0.17 of a standard deviation at ages 16, 26, 30, 34 and 42. In addition, scoring low in both emotional stability and conscientiousness at age 16 is on average even related to an increase in mental ill-health by between 0.25 and 0.35 of a standard deviation in adolescence and adult age for both genders. Higher conscientiousness at age 16 significantly mitigates the positive relation at adult age. The coefficients for mental ill-health in adulthood remain significant also after controlling for mental health problems at age 16, which further emphasizes that apart from an indisputable genetic predisposition, an additional component is likely to contribute to mental health problems.

Psychological models provide valuable insights into the mechanisms of the relation between personality traits and mental health. Ursin and Eriksen (2004)) show that maladaptive and ineffective coping strategies in influenceable challenging situations based on pessimistic expectations are related to feelings of sustained stress that bear the risk of mental ill-health $2^{2}$ Roberts (2009) argues that expectations, feelings and behaviors are stimulated by personality in a non-conscious, repetitive manner so that destructive pat-

\footnotetext{
${ }^{1}$ To assess personality, we make use of the prominent Big Five personality inventory (McCrae and John (1992) or Goldberg (1993)), which contains five personality traits (OCEAN): openness (O), conscientiousness (C), extraversion (E), agreeableness (A) and neuroticism (N). The term neuroticism is contrasted by the term emotional stability, which we mostly use throughout the article.

${ }^{2}$ Coping is defined as "problem-solving thoughts and actions" (Penley et al. (2002), p. 552).
} 


\section{INTRODUCTION}

terns are likely to persist over the life-cycle $3^{3}$ Low emotionally stable individuals are more likely to be worrying, insecure and nervous (Cervone and Pervin (2014)), to have a higher stress-reactivity and to use disengagement and emotion-focused coping strategies such as procrastination and avoidance (Connor-Smith and Flachsbart (2007)). This suggests that low emotionally stable individuals are more likely to be trapped in destructive and unhealthy patterns of expectations, feelings and behavior.

Putting these psychological theories into economic terms, we argue that the individual aims to solve an influenceable, challenging situation with a utility-maximizing level of effort determined by the expected benefits and costs related to that effort. Individuals with lower levels of emotional stability are likely to have lower expected benefits owing to pessimistic believes. This is likely to be related to procrastination or even avoidance behavior, i.e. lower effort. Both discouraging expectations and procrastination or avoidance are likely to contribute to the development of mental health problems, because the perceived and actual problem-solving ability is reduced and the uncomfortable challenge is likely to persist both mentally and actually, i.e. lower utility. However, higher conscientiousness might be able to mitigate the negative relation based on a higher probability of engagement and problem-focused coping (Connor-Smith and Flachsbart (2007)). The extent to which this substitution can exist is theoretically ambiguous and an empirical question.

Focusing on mental health seems to be an economically relevant starting point, because mental health problems are negatively related to important areas in life such as school or work performance (OECD (2011), Tefft (2012), Cornaglia et al. (2015), Bubonya et al. (2016)) and cause high monetary and non-pecuniary costs (Helliwell et al. (2013), Layard et al. (2013), Maclean et al. (2014), Anderson et al. (2015)). There is a line of economic literature that targets extrinsic risks for mental health such as working conditions (Karasek (1979), Karasek and Theorell (1992), Siegrist (1996), Bardasi and Francesconi (2004), Straathof and Weehuizen (2005), Cottini and Lucifora (2013), Hudson and Barrett (2014), Drydakis (2015)), environmental shocks (Lindeboom et al. (2002), Cesur et al. (2013), Cornaglia et al. (2014), Dustmann and Fasani (2016), Danzer and Danzer (2016)) or family characteristics (Johnston et al. (2013), Layard et al. (2014), Persson and RossinSlater (2016)).

In contrast to these studies, we build on the emerging economic literature that focusses on intrinsic risks for psychological and physical health related to variation in expectations, behaviors and feelings. For instance, some studies suggest that individuals with an internal locus of control expect higher returns to health-related activities (Cobb-Clark et al. (2014)) and are more likely to invest in healthy activities (Mendolia and Walker (2014)) $4^{4}$ Further, Blázquez Cuesta and Budría (2015) analyze the relation between income deprivation and mental health outcomes finding that low emotionally stable people are more deprivation-sensitive than emotionally stable individuals. However, these studies do not

\footnotetext{
${ }^{3}$ However, according to Roberts (2009), environmental (e.g. family background, working conditions) and biological factors (e.g. gender) also play a role for variation in thoughts, feelings and behavior. However, in this article, we focus on the role of personality traits that are likely to influence how individuals cope with everyday problems as well as when facing serious challenges.

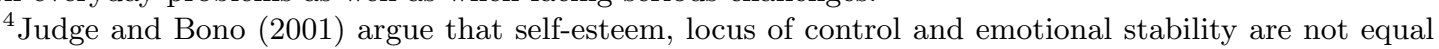
but related psychological concepts.
} 


\section{THEORETICAL CONSIDERATIONS}

provide a coherent framework of possible mechanisms and there are in general only a few attempts to integrate psychological concepts into economic models (Ruhm (2012), Rustichini et al. (2012), Caliendo et al. (2015), Polachek et al. (2015)), because the relation between psychological concepts and socioeconomic outcomes is not straightforward and more complicated mechanisms are likely to play a large role.

We target this research gap and contribute to the understanding of the variation in mental health outcomes throughout life related to personality differences. Therefore, we (1) investigate and connect psychological models and put the insights gained into an economic framework, (2) analyze the predictive power of emotional stability and other personality traits at adolescence for mental health problems at young and older age, (3) test the potential substitution effect of conscientiousness for the relation between emotional stability and mental health problems at various ages and (4) discuss implications that relate low emotional stability and low conscientiousness to an increased risk of socioeconomic disadvantage. Thus, our study provides an important contribution to the economic literature. In the next sections, we discuss our theoretical considerations, before we subsequently introduce the data and present our results. Finally, we conclude and provide policy implications.

\section{Theoretical Considerations}

In a first step, we explore the psychological literature to learn more about the relation between personality and mental health outcomes. We relate our theoretical considerations to the example of an exam at school considering that its outcome is influenceable by the individual. In a second step, we put the insights gained into an economic framework, which we subsequently test regarding the relation between personality and mental health problems.

\subsection{Insights from Psychology}

Psychological literature offers some important insights that help to understand the relationship between emotional stability as well as conscientiousness and mental health outcomes. Personality psychologists show that differences in personality traits are related to variation in coping styles, i.e. problem-solving thoughts and actions. Psychologist often distinguish between emotion- versus problem-focused coping (Lazarus and Folkman (1984)) or disengagement versus engagement coping (Rothbaum et al. (1982)). Emotion-focused and disengagement coping strategies aim to reduce negative emotions by keeping distance from the source of stress, whereas problem-focused and engagement coping aim to reduce or to resolve the cause of stress and to gain control over the stressor. Low emotional stability is typically related to emotion-focused and disengagement coping strategies, while conscientiousness is considered to be associated with problem-focused and engagement coping strategies (Campbell-Sills et al. (2006)) .5 $^{5}$ In view of facing an exam, problem-focused and

\footnotetext{
${ }^{5}$ See Connor-Smith and Flachsbart (2007). Various coping structures exist. An overview about different structures of coping and it's relation to personality is provided by for instance Compas et al. (2001), Skinner et al. (2003), Connor-Smith and Flachsbart (2007).
} 


\section{THEORETICAL CONSIDERATIONS}

engagement coping relates to the proper preparation of the exam to gain control over its outcome, while emotion-focused and disengagement coping is associated with deferring the exam preparation to reduce negative emotion.

To gain deeper insights, Ursin and Eriksen (2004)'s Cognitive Activation Theory of Stress is useful, arguing that individuals react with arousal when they are confronted with a stimulus that is defined as the discrepancy between what the individual expects and what happens in reality. The announcement of an exam in school might be considered as a negative and threatening stimulus. Individuals "report this as stress" (Ursin and Eriksen (2004), p. 571), whereby the extent of stress depends on the student's stimulus expectancies 5 , which are based on previous experiences and learning and are expected to differ with the level of emotional stability that has the strongest stress association (Eysenck (1988), Ebstrup et al. (2011), Cervone and Pervin (2014)). This suggests that it is likely that less emotionally stable individuals perceive more exams in school as threatening compared with more emotionally stable individuals and that low emotionally stable individuals are likely to perceive an exam as more threatening compared with more emotionally stable individuals. Accordingly, Connor-Smith and Flachsbart (2007) state "personality may affect coping strategy selection directly, by constraining or facilitating use of specific strategies, or indirectly, by influencing the nature and severity of stressors experienced [...] the treat sensitivity underlying $\mathrm{N}$ may trigger disengagement [...] $\mathrm{N}$ is associated with high rates of stress exposure and intense emotional and physiological reactivity to stress" (p. 1081) 7

The stress response is uncomfortable but not per se problematic regarding mental health outcomes. It is much more a "safety system, which guarantees priority to serious and sudden discrepancies" (Ursin and Eriksen (2004), p. 573). Therefore, phasic stress is vitally important to find proper solutions in challenging situations, i.e. it might initiate a proper exam preparation. Nonetheless, feelings of stress persist until the problem is at least mentally solved and "sustained arousal may lead to pathology" (Ursin and Eriksen (2004), p. 570).

Whether the individual's arousal in the challenging exam situation causes harmless phasic or damaging sustained stress depends on his/her response outcome expectancy, which is also based on previous experiences and learning and is assumed to vary with the level of emotional stability. "When the subject has learned that performance of a response [...] brings a certain outcome [...] this is referred to as response outcome expectancy" (Ursin and Eriksen (2004), p. 573). Response outcome expectancies are defined as positive (coping), negative or uncertain. Coping is defined as the positive response outcome expectancy and means that the student has established the expectancy to be able to handle the exam with a positive result. Coping leads to harmless, phasic stress. An uncertain or negative outcome expectancy is much more problematic. An uncertain response outcome expectancy means that the individual cannot recognize a relationship between the response and the outcome and thus the student perceives having no control over the exam's outcome. By contrast, a negative response outcome expectancy reflects

\footnotetext{
6 "When the subject has learned that one stimulus [...] predicts the occurrence of another event [...] this is referred to as stimulus expectancy" (Ursin and Eriksen (2004), p. 573).

${ }^{7} \mathrm{~N}$ refers to the personality trait neuroticism.
} 


\section{THEORETICAL CONSIDERATIONS}

the opposite of coping, i.e. the student expects exam failure whatever he/she does and considers this as his/her fault, which is related to a feeling of guilt. Both uncertain and negative response outcome expectancies are related to harmful sustained stress because the perceived individual problem-solving ability is reduced and the challenge mentally persists.

Low emotionally stable individuals are prone to anxiety, chronic worry, distress and maladaptive coping strategies (Cervone and Pervin (2014), p. 265). This suggests that low emotional individuals are likely have a reduced perceived problem-solving ability based on negative or uncertain response outcomes expectancies, which is related to uncomfortable sustained stress. Emotion-focused and disengagement coping might reduce these negative emotions and produce relief, which can be considered a short-run gain. However, procrastination or avoidance i.e. a reduced actual problems-solving ability is likely to result in a worsened exam result. Thus, a vicious circle based on negative expectations and negative experiences is completed and likely to be sustained. Accordingly, Connor-Smith and Flachsbart (2007) argue that "although N may facilitate disengagement, and make it beneficial in the short-term, these immediate benefits for vulnerable individuals are likely outweighed by long-run costs" (p. 1102). Furthermore, "short-term, personality-related benefits of disengagement for $\mathrm{N}$ individuals may amplify the direct effect of $\mathrm{N}$ on the tendency to disengage, explaining why $\mathrm{N}$ individuals continue to use strategies that produce poor long-term results" (p. 1082) 8

By contrast, conscientious individuals are more likely to apply problem-focused and engagement coping strategies (Connor-Smith and Flachsbart (2007)) and are considered as organized, persistent and ambitious (Cervone and Pervin (2014)). In the context of the exam preparation, conscientious students are more likely to establish and refine an appropriate work organization and a proper time management, but also to have the selfdiscipline to realize the own plan. Being able to rely on such skills and routines is likely to increase control and decrease arousal in influenceable challenging situations so that less emotionally stable, but more conscientious individuals are less likely to experience sustained stress and mental health issues compared with low emotionally stable individuals who score lower in conscientiousness. Further, these skills and routines increase the probability of being properly prepared and of being able to effectively cope with influenceable challenges so that the also the exam outcome is likely to be better.

Roberts (2009) argues that states of thoughts (expectancies), feelings (arousal) and behaviors (avoidance or effort) are to some extent triggered by personality traits in an unconscious, repetitive manner. Therefore, we have three hypotheses for our analysis. First, under the assumption that individuals are confronted with various smaller and larger challenges day-by-day (e.g. in school or at work as well as in social relations), situations where feelings of sustained stress related to destructive expectations and avoidance behavior may occur are likely to cumulate particularly for less emotionally stable individuals. This might be associated with mental health problems in the long run. This line of reasoning is consistent with the psychological literature. Based on a meta-analytic review, Penley et al.

\footnotetext{
${ }^{8}$ Again, $\mathrm{N}$ refers to neuroticism, which is used as a synonym for low emotional stability.
} 


\section{THEORETICAL CONSIDERATIONS}

(2002) show that avoidance coping is negatively correlated with mental health outcomes 9 They provide several explanation approaches for the negative relation between avoidance coping and psychological health outcomes, including a further rise in anxiety and worsened outcomes, an impairment of social relations and an increase in unhealthy behaviors such as taking drugs or alcohol. Second, given that personality traits are considered mostly rank-order stable in adult age (Roberts and Del Vecchio (2000), Borghans et al. (2008)), we expect that people who suffer from mental health problems in adolescence are also more likely to suffer from them in older age, because they are likely to be trapped in unhealthy and destructive expectation, feeling and behavior patterns. This is also in line with results from economics (e.g. Roy and Schurer (2013)). Third, we expect that higher conscientiousness is able to substitute for lower emotional stability.

Finally, psychological studies show that school-based mental ill-health prevention programs targeting negative cognition and improved problem-solving abilities may significantly decrease the risk of depressive symptoms (Chaplin et al. (2006), Gillham et al. (2006), Young et al. (2006), Cardemil et al. (2007) or Horowitz et al. (2007)) ${ }^{10}$ However, Horowitz and Garber (2006) and Stice et al. (2009) argue that larger effects result from programs that target high-risk individuals rather than universal programs. "Theoretically, the distress that characterizes high-risk individuals motivates these participants to engage more effectively in the prevention program [...]" (Stice et al. (2009), p. 11). Our article contributes to the literature by further determining groups at-risk based on personality traits within a longitudinal study.

\subsection{Economic Framework}

Putting these insights from the psychological literature into economic terms, we argue that the individual aims to solve an influenceable challenging situation with a utilitymaximizing level of effort determined by the individual's expected benefits and costs related to effort. We consider the development of mental health problems to be influenced by the individual's personality, which affects the individual problem-solving ability. We are particularly interested in neuroticism and conscientiousness.

To illustrate our model, we consider an example of students who face an exam at school. We assume that the exam result fully depends on the student's effort related to exam preparation. Effort can be the time that the student devotes to exam preparation, although it could also represent the intensity with which the student prepares (i.e. concentration). We refrain from any teacher effects and assume that the students have equal initial cognitive ability, live in an equal social environment and have equal biological characteristics. Therefore, students only differ with respect to the personality traits neuroticism and conscientiousness. Following human capital theory, it is assumed that every student makes his/her effort decision in order to maximize the own utility $(U$, e.g. exam grade or

\footnotetext{
${ }^{9}$ See also Folkman and Lazarus (1985), Aldwin and Revenson (1987) or Carver et al. (1989).

${ }^{10}$ Horowitz and Garber (2006), Stice et al. (2009) or Corrieri et al. (2014) provide detailed overviews of existing prevention programs.
} 


\section{THEORETICAL CONSIDERATIONS}

happiness) based on the expected benefits $(B)$ and the costs of effort $(C)$ :

$$
\operatorname{Max} U=B-C
$$

Benefits are the returns to effort, i.e. the grade on the exam or other factors such as parental or labor market recognition. Costs are the costs of effort, i.e. time and energy put in the exam preparation. However, as discussed above, expected benefits $(B)$ are likely to be influenced by the individual personality. Therefore, the utility function can be described such that:

$$
U(f, n, c)=c F(f)+(1-c)(1-n) F(f)-\beta f
$$

The first part of the equation $(c F(f)+(1-c)(1-n) F(f))$ relates to benefits of effort, while the second part $(\beta f)$ equals the costs of effort. Benefits of effort are related to a production function which comprises two elements: a routine component $(c F(f))$ and a non-routine component $((1-c)(1-n) F(f))$. The routine component is related to universally relevant skills such as an appropriate work organization and time management, but also the ambition and self-discipline to realize the own plan. These skills are likely to increase the translation of effort into utility and, as shown above, they are related to conscientiousness $(c, 0<c<1)$. Thus, the higher conscientiousness, the higher the probability that the individual establishes and refines these skills. Related to the example of the exam preparation, this means that the more conscientious student is more likely to have his/her learning material completed and organized, is more likely to have a schedule prepared that splits the learning content into smaller and better digestible pieces, is more likely to stick to his/her learning schedule, and thus, is more likely to have enough time to clarify open questions. Therefore, the routine-based component $(c F(f))$ is related to a gain of control over the challenge's outcome and a decrease of arousal in the challenging situation so that the translation of effort into utility is not hindered by negative or distracting emotions and cognition.

However, another part of the challenge is related to entering new territory so that reliance on preparation and previous developed skills is impossible. The non-routine component $((1-c)(1-n) F(f))$ involves two types of production losses. First, the production loss increases with the non-routine character of the task, which is negatively related to conscientiousness $(1-c)$. Second, the production loss increases with neuroticism $(1-n$, $0<n<1)$. From the psychological literature, we have learned that the level of neuroticism affects the extent to which the student considers the exam as a challenge. Taking into account that the exam is decisive for the student's future, it can potentially be threatening to the student and might work as a stress stimulus. A student with a higher level of neuroticism is probably more stressed about living up to the teacher's expectations and is expected to experience a higher level of arousal. This is leaving him/her with an uneasy feeling and the neurotic student is likely to devote effort to eliminate this uncomfortable arousal. This is expected to lower his/her grade, but also his/her happiness compared with a student who is less neurotic. 


\section{THEORETICAL CONSIDERATIONS}

Finally, the cost of effort are related to a scaling factor $(\beta)$ times the effort $(f)$ put. The benefit function is positive and upward sloping, albeit at diminishing marginal returns to effort or concave. The cost function is assumed to be linear and increasing with effort.

The student aims at maximized utility levels and he/she can choose an effort level to achieve this. Let's assume that $F(f)=f^{\alpha}$ with $0<\alpha<1$ so that:

$$
U(f, n, c)=c f^{\alpha}+(1-c)(1-n) f^{\alpha}-\beta f
$$

The optimal level of effort $f^{*}$ to face the challenge of the exam is found by solving the first-order condition with respect to effort. From this condition the optimal effort $f^{*}$ can be derived (Equation 2):

$$
\begin{aligned}
\frac{\partial U}{\partial f} & =\alpha c f^{\alpha-1}+\alpha(1-c)(1-n) f^{\alpha-1}-\beta=0 \\
f^{*} & =\left(\frac{\beta}{\alpha(1-n+c n)}\right)^{\frac{1}{\alpha-1}}
\end{aligned}
$$

The student's optimal effort level is affected by his/her personality, here neuroticism $(n)$ and conscientiousness $(c) . f^{*}$ can be written as a function of $n$ and $c: f^{*}=f^{*}(n, c)$. Taking the partial derivative of Equation 2 with respect to $n$ yields:

$$
\frac{\partial f^{*}}{\partial n}=\frac{1}{\alpha-1} \frac{\beta^{\frac{1}{\alpha-1}} \alpha(1-c)}{(\alpha(1-n+c n))^{\frac{\alpha}{\alpha-1}}}<0
$$

Since $0<\alpha<1,0<\beta<1$ and $0<c<1$, it follows that the first term is negative and the second term is positive. Thus, $f_{n}^{*}<0$ and optimal effort is decreasing in neuroticism.

Taking the partial derivative of Equation 2 with respect to $c$ yields:

$$
\frac{\partial f^{*}}{\partial c}=\frac{1}{\alpha-1} \frac{-\beta^{\frac{1}{\alpha-1}} \alpha n}{(\alpha(1-n+c n))^{\frac{\alpha}{\alpha-1}}}>0
$$

Since $0<\alpha<1,0<\beta<1$ and $0<c<1$, both the first term is negative and the second term is negative (nominator is negative and denominator is positive). Thus, $f_{c}^{*}>0$ and optimal effort is increasing in conscientiousness.

Further, the substitution effect of conscientiousness $c$ on optimal effort related to neuroticism $f_{n}^{*}$ can be derived:

$$
\frac{\partial^{2} f^{*}}{\partial n \partial c}=-\alpha \beta^{\frac{1}{\alpha-1}}\left(\frac{\alpha^{2}-\alpha(1-n+c n)}{(\alpha-1)^{2}(\alpha(1-n+c n))^{\frac{\alpha}{\alpha-1}+1}}\right)>0
$$

Given that both terms are negative, it is shown that the substitution effect of $c$ on optimal effort $f_{n}^{*}$ is positive $\left(f_{n c}^{*}>0\right)$.

Next, the relation between optimal utility $U^{*}$, neuroticism $n$ and conscientiousness $c$ is 


\section{THEORETICAL CONSIDERATIONS}

derived. Optimal utility $U^{*}$ can be written as:

$$
U^{*}\left(f^{*}, n, c\right)=f^{\alpha}(1-n+c n)-\beta f^{*}
$$

Optimal effort $f^{*}$ is:

$$
f^{*}=\beta^{\frac{1}{\alpha-1}}(\alpha(1-n+c n))^{\frac{1}{1-\alpha}}
$$

Putting optimal effort $f^{*}$ into optimal utility $U^{*}$ yields:

$$
\begin{aligned}
U^{*}\left(f^{*}, n, c\right) & =\left(\beta^{\frac{1}{\alpha-1}}(\alpha(1-n+c n))^{\frac{1}{1-\alpha}}\right)^{\alpha}(1-n+c n) \\
& -\beta\left(\beta^{\frac{1}{\alpha-1}}(\alpha(1-n+c n))^{\frac{1}{1-\alpha}}\right)
\end{aligned}
$$

Taking the partial derivative of Equation 3 with respect to $n$ yields:

$$
\frac{\partial U^{*}}{\partial n}=-\beta^{\frac{\alpha}{\alpha-1}}(1-c)(\alpha(1-n+c n))^{\frac{\alpha}{1-\alpha}}<0
$$

Given that $-\beta^{\frac{\alpha}{\alpha-1}}<0,1-c>0$ and $\left.\alpha(1-n+c n)\right)^{\frac{\alpha}{1-\alpha}}>0$, it follows that $U_{n}^{*}<0$. Optimal utility is decreasing in neuroticism. Based on the psychological literature, it is expectable that neurotic students are more likely to suffer from sustained stress and to procrastinate or even avoid the challenging exam preparation. Thus, general discomfort is likely and the exam grade achieved is probably lower for the procrastinating or avoiding student compared to a student who actively targets the influenceable challenge. In sum, this scenario is related to a reduced utility for the neurotic student.

Taking the partial derivative of Equation 3 with respect to $c$ yields:

$$
\frac{\partial U^{*}}{\partial c}=n \beta^{\frac{\alpha}{\alpha-1}}(\alpha(1-n+c n))^{\frac{\alpha}{1-\alpha}}>0
$$

Given that $n \beta^{\frac{\alpha}{\alpha-1}}>0$ and $\alpha(1-n+c n)^{\frac{\alpha}{1-\alpha}}>0$, it follows that $U_{c}^{*}>0$. Optimal utility is increasing in conscientiousness. Conscientious individuals are by definition organized, ambitious and self-disciplined and more likely to use problem-focused coping so that the conscientious student is probably better prepared, less aroused and receives a better grade in the exam.

Moreover, conscientiousness can potentially mitigate the positive relation between neuroticism and mental health problems. To observe this, we derive $U_{n c}^{*}$, which yields:

$$
\frac{\partial^{2} U^{*}}{\partial n \partial c}=\beta^{\frac{\alpha}{\alpha-1}}\left(\frac{1-\alpha-n+c n}{1-\alpha-n+c n+\alpha n-\alpha c n}(\alpha(1-n+c n))^{\frac{\alpha}{1-\alpha}}\right)>0
$$

Given that $\beta^{\frac{\alpha}{\alpha-1}}>0$ and $(\alpha(1-n+c n))^{\frac{\alpha}{1-\alpha}}>0, U_{n c}^{*}>0$. This substitution effect 
is generally positive. However, for very high levels of neuroticism in relation to conscientiousness, though, or when $n>\frac{1-\alpha}{1-c}$, the substitution effect is negative. This means that for extremely neurotic individuals, conscientiousness is no "rescue" for taking up the challenge.

Our theoretical considerations suggest that low emotionally stable individuals are more likely to react with procrastination or avoidance in challenging situations based on shortrun gains related to a reduction of negative emotion. However, these benefits are likely to be outweighed by the long-run costs. Nevertheless, these short-term benefits of procrastination or avoidance as well as the self-fulfilling prophecy related to destructive expectations and negative experiences make it likely that low emotionally stable individuals unconsciously and repetitively make use of maladaptive and ineffective coping strategies related to poor long-term outcomes. Therefore, low emotionally stable individuals are likely to be trapped in a self-sustained circle of mental health risk which is related to multidimensional disadvantage.

Behavioral economists might interpret this scenario as variation in economic preferences. Accordingly, low emotionally stable individuals might be present-biased and prefer the short-run relief, while they discount possible future losses. In contrast, we suppose that the scenario should be rather interpreted as a rational, but biased choice than as naive hyperbolic discounting 11 In this context, the individual choice is considered as primarily rational, which is in line with the standard economic framework. However, it is biased, because the foresight of low emotionally stable individuals is likely to be more pessimistic compared to more emotionally stable individuals due to higher arousal and destructive thoughts ${ }^{12}$ Choosing present gains in favor of uncertain or unlikely future benefits is rather rational than a naive preference. However, our economic framework suggests that the biased expectations of highly neurotic individuals are likely to be related to an individual welfare loss based on an increased risk of mental ill-health and socioeconomic disadvantage ${ }^{13}$ This scenario is related to market failure and suggests that a reduction of the expectation bias based on a decrease of sustained arousal and negative cognition might reduce mental health problems and improve various socioeconomic outcomes. Higher conscientiousness can be regarded as a proxy for a more organized and conscious mindset that is likely to reduce the noise adhered to process of decision-making and problem-solving.

In the next sections, these theoretical considerations are tested empirically regarding their implication for the relationship between personality and mental health outcomes.

\section{Data}

We make use of the 1970 British Cohort Study (BCS70), which is conducted by the Center for Longitudinal Studies (CLS) at the Department for Quantitative Social Science in the Institute of Education at London University and follows the lives of 17,196 people born

\footnotetext{
${ }^{11}$ This idea is related to a forthcoming paper by Gabaix and Laibson (2016).

${ }^{12}$ Initial evidence provide Delaney et al. (2014) who analyze effects of stress on financial decision making and find that the individual discounting rate is increasing with the stress level.

${ }^{13}$ As an example, see for instance Mani et al. (2013) who state that people affected by poverty "often behave in less capable ways, which can further perpetuate poverty" (p. 976).
} 
in England, Scotland and Wales during one week in 1970. The BCS70 provides detailed information about the individual's family background, cognitive ability, personality and indicators of mental health problems.

Appendix Table 8 provides an overview of the BCS70 datasets used in the analysis, the variables investigated and the general number of observations in each of the eight waves. The initial number of observations (unrestricted sample) presented in Appendix Table 8 is not congruent with the actual number of observations (working sample) used in the analysis due to panel attrition and missing values within our variables of interest. Our working sample restricts for the availability of the personality traits emotional stability, conscientiousness, agreeableness and extraversion at ages 10 and 16, cognitive ability at age 10, mother's age, parental socioeconomic status and region of birth as well as one mental ill-health score at a time, resulting in five separate samples with 2559 (age 16), 3436 (age 26), 4200 (age 30), 3789 (age 34) and 3369 (age 42) observations.

We look into the issue of sample selection by descriptively comparing our working sample with the unrestricted sample (Appendix Section B) and conclude that our results suffer from positive selection. On average, people in our working sample less commonly suffer from problematic characteristics such as low emotional stability, low extraversion, low conscientiousness, and mental health problems, but have higher cognitive ability, are from a more advantaged socioeconomic background, and have slightly older mothers. This is an intuitive result given that people with less preferable characteristics such as low conscientiousness, are less likely to continuously participate in the survey. The result further suggests that the individuals who are not covered at all by the survey presumably have even worse characteristics. Therefore, we expect that we estimate lower bound results and that the observed associations are even more oppressive in the unrestricted sample.

To test the robustness of our results, we conduct two tests. First, we repeat all descriptives and analyses based on a fully restricted sample, which restricts for the availability of all variables used and includes 1,270 observations. Second, we perform multiple imputation with regard to our indicator of mental health problems and the personality trait variables resulting in an increase of the sample size with 3142 (age 16), 4066 (age 26), 4910 (age 30), 4399 (age 34) and 3878 (age 42) observations. Both procedures show that the results are consistent with our main results and are available upon request.

\subsection{Mental Health Problems}

Our indicator of mental health problems is assessed by Rutter et al. (1970)'s Malaise Inventory, which is measured at ages 16, 26, 30, 34 and 42 and that covers emotional disturbance and associated physical symptoms (UK Data Service (2016)). The Malaise Inventory is based on the Cornell Medical Index Health Questionnaire (CMI), which comprises 195 self-completion questions (Brodman et al. (1949), Brodman et al. (1952)).

The internal consistency and validity of the Malaise Inventory has been tested and shown to hold in various socioeconomic groups (Rodgers et al. (1999)) and has been used in many studies (Rutter and Madge (1976), McGee et al. (1986), Grant et al. (1990)). Rutter et al. (1970) confirm that "the inventory differentiates moderately well between 
Figure 1: Mental Health Problems at Ages 16, 26, 30, 34 and 42

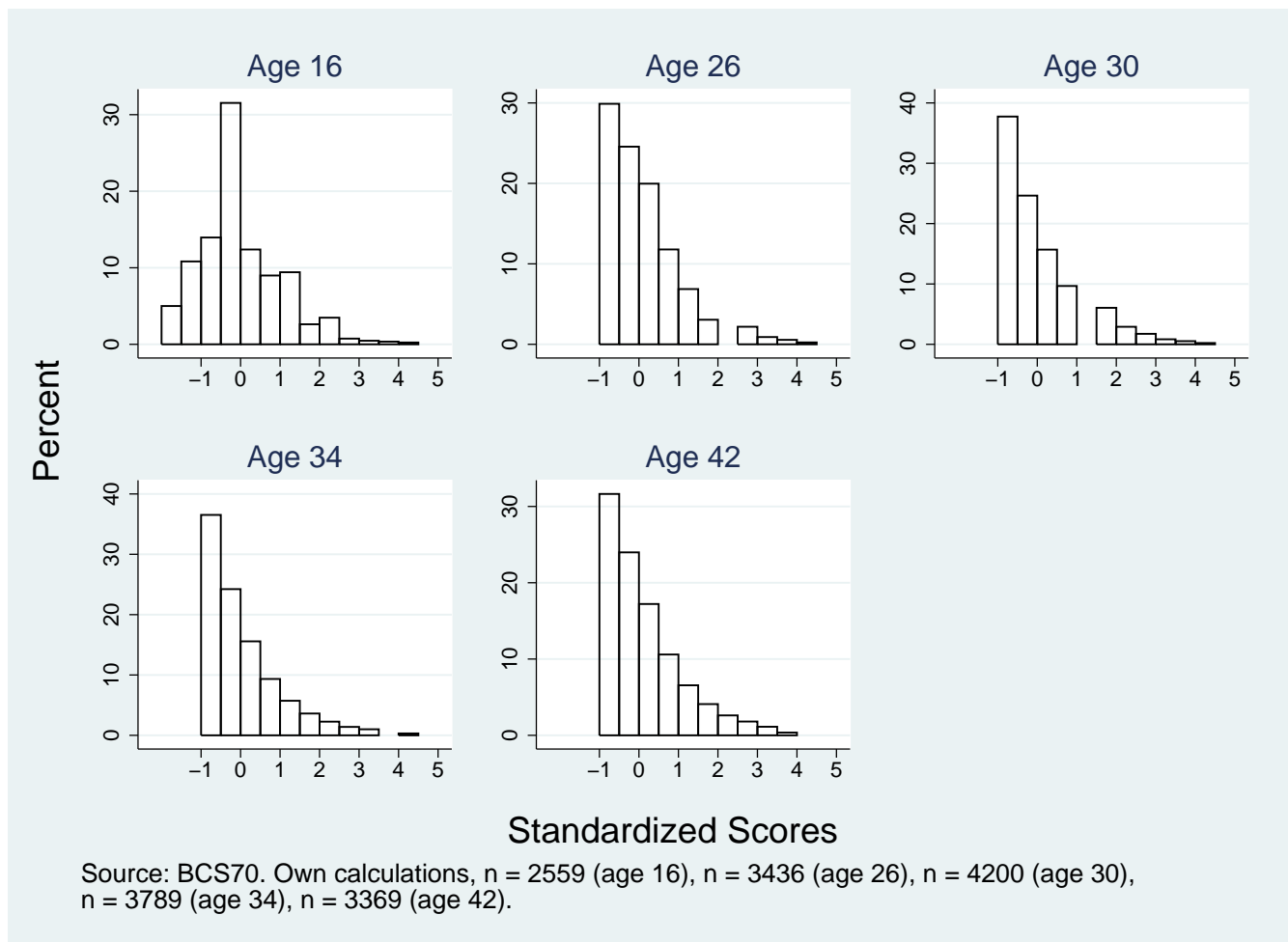

individuals with and without psychiatric disorder" (p. 160, see UK Data Service (2016)). The Malaise Inventory include questions such as "Do you feel tired most of the time?", "Do you often feel depressed?" and "Do you often get worried about things?" The items are coded to the rule "the worse the mental ill-health symptom, the higher the item value." The individual malaise score by wave is generated by summing up the responses to the item set.

Both the number of items within the item set and the measurement scale vary between waves. At age 16, the item set includes 22 items, whereby the malaise items are measured on a three-point scale with the categories 0 "rarely or never," 1 "some of the time" and 2 "most of the time." At ages 26 and 30, the item set includes 24 items, while at ages 34 and 42, it includes only 9 items. At ages 26, 30, 34 and 42, the malaise items are measured on a two-point scale with the categories 0 "no" and 1 "yes."

Appendix Table 9 provides an overview of the questions, the availability of each item for different ages, the measurement scales for the items, the measurement scales for the sum scores and the threshold that is regarded as a sign that the respondent experiences symptoms related to depression. To make the mental ill-health variable comparable between different ages, we restrict our score for mental health problems to the nine questions that are available in all five waves. Therefore, the questions used are the items $2,3,5$, 9, 12, 14, 16, 20, and 21 (marked in bold in Appendix Table 9). Only individuals who have zero missing values in the nine items are taken into account in the analysis. We use standardized mental ill-health scores in our analysis. Figure 1 depicts the distribution 
of mental health problems. The scores are standardized based on the restricted working sample.

Table 1 shows the correlation coefficients for the mental ill-health scores at ages 16, 26, 30, 34 and 42. The size of the correlation coefficients moves between 0.26 and 0.57 . The results show that mental health problems seem to be more malleable in younger age, while they seem to be more stable at older age: the correlation between mental health problems at ages 16 and 26 is only 0.39 and is 0.56 or 0.57 between ages 26 and 30, ages 30 and 34 as well as ages 34 and 42 .

Table 1: Correlation of Mental Ill-Health Scores between Ages 16 and 42

\begin{tabular}{lllll}
\hline & Age 16 & Age 26 & Age 30 & Age 34 \\
\hline Age 26 & 0.39 & $\cdot$ & $\cdot$ & $\cdot$ \\
Age 30 & 0.35 & 0.57 & $\cdot$ & $\cdot$ \\
Age 34 & 0.35 & 0.50 & 0.56 &. \\
Age 42 & 0.26 & 0.47 & 0.48 & 0.57 \\
\hline
\end{tabular}

Source: BCS70. The sample applied is the fully restricted working sample $(\mathrm{n}=1270)$.

Note: Scores are standardized. Correlation coefficients are significant at the 5 percent level or higher.

\subsection{Personality Traits}

Table 2: Personality Traits at Ages 10 and 16

\begin{tabular}{|c|c|c|c|c|}
\hline $\begin{array}{lr}\text { Personality } & \text { Trait } \\
\text { Constructs } & \text { and } \\
\text { Related Items } & \end{array}$ & $\begin{array}{l}\text { Correlation } \\
\text { Ages } 10 \text { and } \\
16\end{array}$ & $\begin{array}{l}\text { Explained } \\
\text { Variance }\end{array}$ & $\begin{array}{l}\text { Cronbach's } \\
\text { Alpha }\end{array}$ & Items \\
\hline \multicolumn{5}{|l|}{$\begin{array}{l}\text { Emotional Stability } \\
\text { (ES) }\end{array}$} \\
\hline Age 10 & & $53.31 \%$ & 0.82 & R8. Irritable. \\
\hline Age 16 & 0.40 & $55.63 \%$ & 0.84 & $\begin{array}{l}\text { R9. Miserable and tearful. } \\
\text { C8. Requests must be met immediately. } \\
\text { C12. Sullen or sulky. } \\
\text { C16. Changes mood quickly and drastically. } \\
\text { C17. Outburst of temper unpredictable. }\end{array}$ \\
\hline \multicolumn{5}{|l|}{$\begin{array}{l}\text { Conscientiousness } \\
\text { (C) }\end{array}$} \\
\hline Age 10 & & $66.34 \%$ & 0.83 & R15. Cannot settle. \\
\hline Age 16 & 0.44 & $63.98 \%$ & 0.81 & $\begin{array}{l}\text { C3. Inattentive, easily distracted. } \\
\text { C13. Fails to finish things. } \\
\text { C19. Difficulty concentrating on task. }\end{array}$ \\
\hline \multicolumn{5}{|l|}{ Agreeableness (A) } \\
\hline Age 10 & & $46.90 \%$ & 0.81 & R3. Destroys own or others' belongings. \\
\hline Age 16 & 0.31 & $38.93 \%$ & 0.74 & $\begin{array}{l}\text { R4. Frequently fights with others. } \\
\text { R14. Often disobedient. } \\
\text { R18. Often tells lies. } \\
\text { R19. Bullies other children. } \\
\text { C11. Interferes with other children. } \\
\text { R10. Takes things belonging to others. }\end{array}$ \\
\hline \multicolumn{5}{|l|}{ Extraversion (E) } \\
\hline Age 10 & & $38.21 \%$ & 0.58 & R5. Not much liked by others. \\
\hline Age 16 & 0.37 & $36.89 \%$ & 0.56 & $\begin{array}{l}\text { R6. Often worried. } \\
\text { R7. Rather solitary } \\
\text { R16. Afraid of new things or situations. } \\
\text { R17. Fussy or over-particular. }\end{array}$ \\
\hline
\end{tabular}

Source: BCS70, own calculations based on working sample $\mathrm{n}=2559$.

Note: Correlation coefficients are significant at the 5 percent level or higher. 
Figure 2: Distribution of Personality Traits at Age 10 and 16

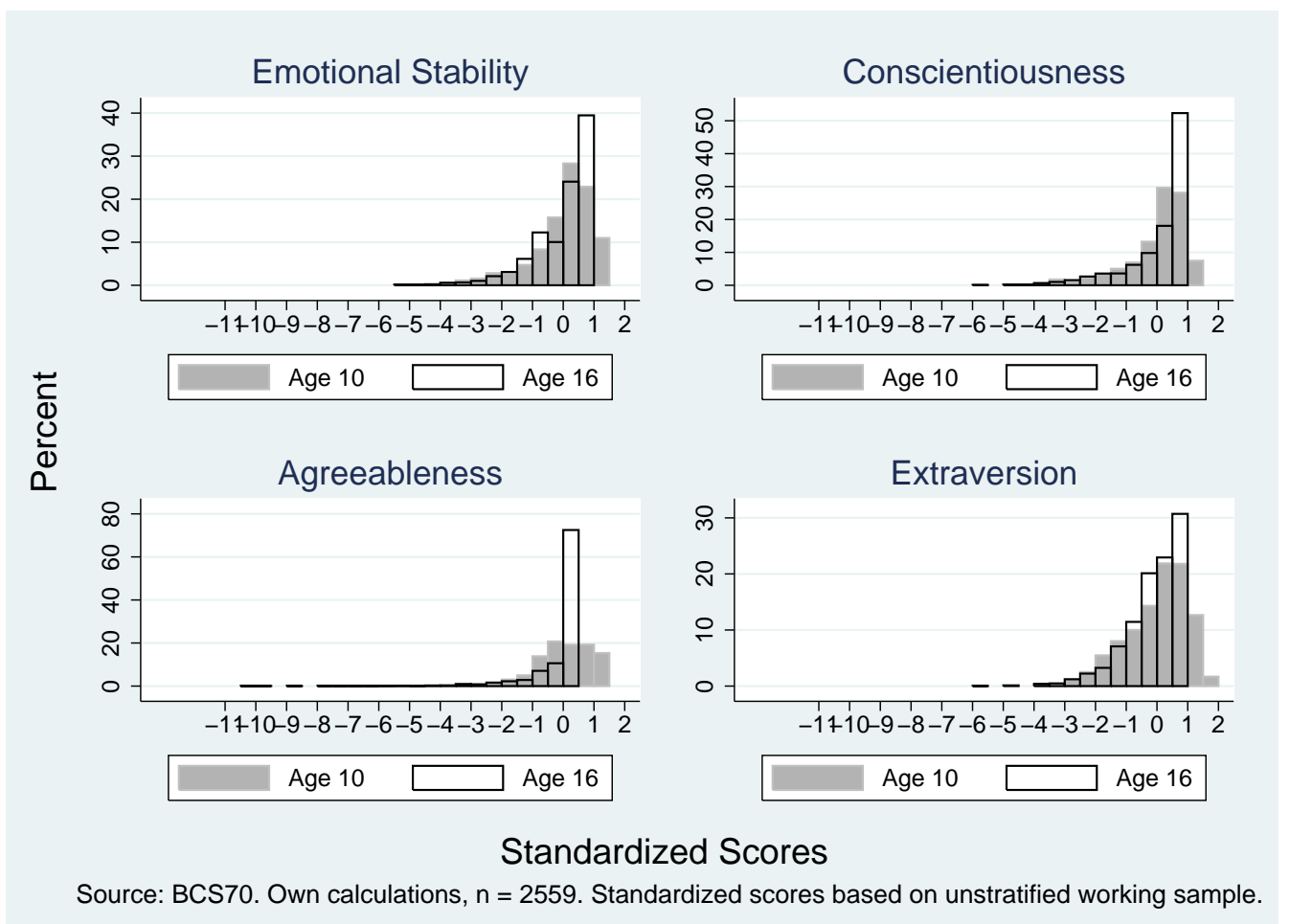

The BCS70 does not directly provide information about the personality traits emotional stability, conscientiousness, agreeableness and extraversion. In order to assess the personality of the individuals in our study, we follow Prevoo and ter Weel (2015), who use BCS70 mother-rated behavior items at ages 10 and 16 and extract emotional stability, conscientiousness, extraversion and agreeableness from an initial set of 38 behavior items. An overview of the variables used is provided in Table 2 .

To extract the first principle component out of the group of behavior items, we standardize the variables so that they have a zero mean and standard deviation of 1 . The resulting personality scores are standardized again depending on the sample definition. We conduct the procedure with the behavior items at ages 10 and 16 to derive personality variables at these ages. An overview of the reliability measures that correspond to the four personality traits is provided in Table 2 . The results are comparable to those reported by Prevoo and ter Weel (2015).

Figure 2 presents the distribution of personality traits at ages 10 and 16 . The graph is based on standardized scores. The underlying working sample restricts for the availability of all variables aside from the mental ill-health indicators. The graph shows that on average individuals change their personality characteristics between ages 10 and 16 which is in line with the literature (Roberts et al. (2006), Lüdtke et al. (2011)).

Taking a brief look at gender differences, our results show that women score higher on agreeableness and conscientiousness than men at both ages 10 and 16. For extraversion, the results are similar for women and men. It further becomes obvious that men score similar on emotional stability to women at age 10 but score higher on emotional stability 
at age 16. This finding is mainly consistent with Schmitt et al. (2008).

\subsection{Additional Controls}

In addition to the measures discussed above, we further control for the individual's cognitive ability. Following Prevoo and ter Weel (2015), this is measured by using test scores at age 10 because at that age cognitive ability can be considered as rank-order stable (Lebel and Beaulieu (2011)). Appendix Table 11 provides all test scores available at age 10. For our analysis, we select the results based on the Shortened Edinburgh Reading Test (ERT), the Friendly Maths Test (FMT), the Pictorial Language Comprehension Test (PLCT) and the diagnostic spelling test, because these tests contain the lowest numbers of missing values and measure a broad range of skills. To assess our measure of cognitive ability, we calculate the share of correct answers per test and derive a standardized score with zero mean and standard deviation of 1 out of these four shares by student.

Furthermore, we control for the child's family background by including the following variables in all our regressions: mother's age, mother's age squared, parental socioeconomic status and region of living at birth. The variable parental socioeconomic status at birth is a binary variable with value 1 or 0 . The variable is coded as 1 if the highest parental occupation status is non-manual, managerial, technical or professional, whereas it is 0 if the child has a non-working single parent, has parents who are unskilled or only partly-skilled or the highest occupation status of the parents is manual work.

\section{Main Results}

Subsection 4.1 targets the predictive power of emotional stability at age 16 for mental health problems in adolescence and adulthood and the relation with conscientiousness and possibly other personality traits. In Subsection 4.2, we address the role of personality change between ages 10 and 16 for mental health outcomes at age 16 and older age. Our results are based on ordinary least square (OLS) regression methods. To account for the possible problem of heteroscedasticity, we calculate robust standard errors.

\subsection{Predictive Power of Personality for Mental Health Problems}

In a first step, we analyze the predictive power of emotional stability and other personality traits at age 16 for mental ill-health at ages 16, 26, 30, 34 and 42. Table 3 presents our results regarding the predictive power of emotional stability and other personality traits at age 16 for mental health problems at ages 16, 26, 30, 34 and 42 .

Our results reveal that emotional stability significantly predicts mental health in adolescence and adulthood and that the size of the coefficients remains relatively stable over time. An increase in emotional stability by 1 standard deviation is related to a decrease in mental health problems by between 0.08 and 0.17 standard deviation. Conscientiousness at age 16 is negatively related to mental health problems, although the coefficients are less robust over time than those for emotional stability. 
Table 3: Personality and Mental Ill-Health over Time

\begin{tabular}{lccccc}
\hline \hline & \multicolumn{5}{c}{ Mental Ill-Health Score } \\
& Age 16 & Age 26 & Age 30 & Age 34 & Age 42 \\
\hline Emotional Stability (Age 16) & $-0.166^{* * *}$ & $-0.109^{* * *}$ & $-0.118^{* * *}$ & $-0.084^{* * *}$ & $-0.115^{* * *}$ \\
& $(0.000)$ & $(0.000)$ & $(0.000)$ & $(0.000)$ & $(0.000)$ \\
Conscientiousness (Age 16) & -0.028 & $-0.058^{* * *}$ & $-0.070^{* * *}$ & $-0.087^{* * *}$ & -0.015 \\
& $(0.256)$ & $(0.005)$ & $(0.000)$ & $(0.000)$ & $(0.479)$ \\
& & & & & \\
Agreeableness (Age 16) & 0.024 & 0.033 & $0.048^{* *}$ & -0.008 & -0.000 \\
& $(0.418)$ & $(0.117)$ & $(0.015)$ & $(0.734)$ & $(0.993)$ \\
Extraversion (Age 16) & $-0.136^{* * *}$ & $-0.124^{* * *}$ & $-0.099^{* * *}$ & $-0.070^{* * *}$ & $-0.120^{* * *}$ \\
& $(0.000)$ & $(0.000)$ & $(0.000)$ & $(0.000)$ & $(0.000)$ \\
Male & & & & & \\
& $-0.329^{* * *}$ & $-0.346^{* * *}$ & $-0.250^{* * *}$ & $-0.239^{* * *}$ & $-0.192^{* * *}$ \\
\hline$N$ & $(0.000)$ & $(0.000)$ & $(0.000)$ & $(0.000)$ & $(0.000)$ \\
$R^{2}$ & 2559 & 3436 & 4200 & 3789 & 3369 \\
\hline \hline
\end{tabular}

$p$-values in parentheses ${ }^{*} p<0.10,{ }^{* *} p<0.05,{ }^{* * *} p<0.01$

Source: British Cohort Study (BCS70), own calculations.

Note: We estimate OLS regressions with robust standard errors and control for mother's age, mother's age squared, parental education at birth, region of birth, and child's cognitive ability at age 10 .

Interestingly, extraversion seems to be another important predictor for mental health at all ages. This could point to an important role of social interaction for mental health. Connor-Smith and Flachsbart (2007) argue that extraversion "may encourage support seeking [and is associated] with low stress-reactivity and positive appraisal of available coping resources" (p. 1081). Based on a cognitive-behavioral and social problem-solving intervention designed to reduce and prevent depressive symptoms among girls, Chaplin et al. (2006) find that significantly positive effects might arise due to the participant's social interaction, which is related to friendships and exchange about destructive thoughts, problems and ways how to overcome them. However, also addressing the role of extraversion theoretically and empirically in detail goes beyond the scope of this article.

It is further shown that women are more often affected by mental ill-health than men at all ages. This result is in accordance with the psychological literature about gender differences regarding to depressive symptoms (Hankin et al. (1998), Broidy et al. (2003)).

In a second step, we include interaction terms between above- and below-mean emotional stability and conscientiousness to control for the expected interaction effects between emotional stability and conscientiousness. In Table 4, we check the association between the interaction of emotional stability and conscientiousness with mental health outcomes. Thereby, we build above- and below-mean combinations between the two traits (more emotionally stable and more conscientious, more emotionally stable and less conscientious, less emotionally stable and more conscientious, and less emotionally stable and less conscientious). The reference group comprises individuals who score high in both emo- 
Table 4: Personality Trait Interaction and Mental Ill-Health over Time

\begin{tabular}{|c|c|c|c|c|c|}
\hline & \multicolumn{5}{|c|}{ Mental Ill-Health Score } \\
\hline & Age 16 & Age 26 & Age 30 & Age 34 & Age 42 \\
\hline High Emotional Stability, & 0.092 & 0.054 & $0.142^{* * *}$ & $0.085^{*}$ & -0.012 \\
\hline Low Conscientiousness (Age 16) & $(0.147)$ & $(0.297)$ & $(0.003)$ & $(0.079)$ & $(0.818)$ \\
\hline Low Emotional Stability, & $0.251^{* * *}$ & 0.067 & $0.113^{* *}$ & $0.096^{* *}$ & $0.154^{* * *}$ \\
\hline High Conscientiousness (Age 16) & $(0.000)$ & $(0.151)$ & $(0.011)$ & $(0.039)$ & $(0.002)$ \\
\hline Low Emotional Stability, & $0.305^{* * *}$ & $0.263^{* * *}$ & $0.338^{* * *}$ & $0.310^{* * *}$ & $0.245^{* * *}$ \\
\hline Low Conscientiousness (Age 16) & $(0.000)$ & $(0.000)$ & $(0.000)$ & $(0.000)$ & $(0.000)$ \\
\hline Agreeableness (Age 16) & -0.016 & -0.004 & 0.012 & $-0.037^{*}$ & -0.021 \\
\hline & $(0.577)$ & $(0.831)$ & $(0.493)$ & $(0.092)$ & $(0.340)$ \\
\hline Extraversion (Age 16) & $-0.158^{* * *}$ & $-0.143^{* * *}$ & $-0.115^{* * *}$ & $-0.082^{* * *}$ & $-0.131^{* * *}$ \\
\hline & $(0.000)$ & $(0.000)$ & $(0.000)$ & $(0.000)$ & $(0.000)$ \\
\hline Male & $-0.343^{* * *}$ & $-0.356^{* * *}$ & $-0.263^{* * *}$ & $-0.242^{* * *}$ & $-0.198^{* * *}$ \\
\hline & $(0.000)$ & $(0.000)$ & $(0.000)$ & $(0.000)$ & $(0.000)$ \\
\hline$N$ & 2559 & 3436 & 4200 & 3789 & 3369 \\
\hline$R^{2}$ & 0.097 & 0.096 & 0.066 & 0.065 & 0.062 \\
\hline
\end{tabular}

$p$-values in parentheses ${ }^{*} p<0.10,{ }^{* *} p<0.05,{ }^{* * *} p<0.01$

Source: British Cohort Study (BCS70), own calculations.

Note: We estimate OLS regressions with robust standard errors and control for mother's age, mother's age squared, parental education at birth, region of birth, and child's cognitive ability at age 10.

tional stability and conscientiousness, i. e. theoretically considered as the most favorable combination.

We find that the most problematic combination with respect to the two personality traits of interest is low emotional stability and low conscientiousness at all ages for both women and men. Thus, scoring low on both emotional stability and conscientiousness is on average related to an increase in mental ill-health by between 0.25 and 0.35 of a standard deviation. This result is in line with our theoretical considerations in Section 2 , Accordingly, individuals who score low in both emotional stability and conscientiousness are more likely to have a reduced perceived and actual problem-solving ability related to pessimistic expectations and emotion-focussed coping strategies also in influenceable challenging situation throughout life. This is likely to be related to feelings of sustained stress, an increase in anxiety and worse outcomes because the challenge mentally and actually persists. In the long run, mental ill-health might arise and endure.

Scoring higher in conscientiousness seems to be able to mitigate the negative relation between emotional stability and mental health problems. Indeed, respondents who score low in emotional stability but higher in conscientiousness are also significantly more likely to experience mental ill-health compared with individuals who score both high in emotional stability and conscientiousness. However, starting at the age of 26, they are (borderline) 
Table 5: Personality and Mental Ill-Health over Time

\begin{tabular}{lcccc}
\hline \hline & \multicolumn{4}{c}{ Mental Ill-Health Score } \\
& Age 26 & Age 30 & Age 34 & Age 42 \\
\hline Emotional Stability (Age 16) & $-0.122^{* * *}$ & $-0.080^{* * *}$ & -0.050 & $-0.126^{* * *}$ \\
& $(0.000)$ & $(0.004)$ & $(0.105)$ & $(0.000)$ \\
Conscientiousness (Age 16) & $-0.050^{*}$ & $-0.046^{*}$ & $-0.096^{* * *}$ & -0.013 \\
& $(0.083)$ & $(0.079)$ & $(0.001)$ & $(0.646)$ \\
Agreeableness (Age 16) & $0.060^{*}$ & 0.035 & -0.005 & 0.044 \\
& $(0.069)$ & $(0.247)$ & $(0.911)$ & $(0.222)$ \\
Extraversion (Age 16) & $-0.054^{* *}$ & $-0.051^{* *}$ & -0.033 & $-0.087^{* * *}$ \\
& $(0.030)$ & $(0.028)$ & $(0.200)$ & $(0.001)$ \\
Malaise Score (Age 16) & $0.113^{* * *}$ & $0.103^{* * *}$ & $0.097^{* * *}$ & $0.078^{* * *}$ \\
& $(0.000)$ & $(0.000)$ & $(0.000)$ & $(0.000)$ \\
Male & & & & $-0.204^{* * *}$ \\
& $-0.289^{* * *}$ & $-0.178^{* * *}$ & $-0.186^{* * *}$ & $(0.000)$ \\
\hline$N$ & $(0.000)$ & $(0.000)$ & $(0.000)$ & 1797 \\
$R^{2}$ & 1907 & 2149 & 1983 & 0.135 \\
\hline \hline
\end{tabular}

$p$-values in parentheses ${ }^{*} p<0.10,{ }^{* *} p<0.05,{ }^{* * *} p<0.01$

Source: British Cohort Study (BCS70), own calculations.

Note: We estimate OLS regressions with robust standard errors and control for mother's age, mother's age squared, parental education at birth, region of birth, and child's cognitive ability at age 10 .

significantly less likely to have mental health issues compared with those who score low in both emotional stability and conscientiousness.

This result might be related to positive success experiences that are more likely to take place when the respondent overcomes the tendency to avoid challenges, but acts more problem-focused based on higher conscientiousness. Accordingly, the individual's own perceived and actual problem-solving ability might be improved so that sustained stress and mental ill-health holds lesser concern. This argumentation is supported by CampbellSills et al. (2006) who argue that "the tendency to respond to stressful situations with an active, problem-solving approach promotes resilience in conscientious individuals" ( $p$. 585). Regarding to both tables, we did not find significant gender differences.

However, one could argue that mental health problems at both adolescent and adult age are to a major extent related to a genetic predisposition and not to behavioral differences. Hence, emotional stability at age 16 would only reflect mental ill-health at age 16 in the regressions for the older ages. To test for this, the regressions in Tables 3 and 4 are repeated for the ages 26, 30, 34 and 42 by additionally controlling for mental health at age 16. The results are presented in Tables 5 and 6. The tables show that an 1 point increase of the malaise score at age 16 is on average associated with a mental ill-health increase of around 0.1 of a standard deviation at older ages. Further, controlling for mental health 
Table 6: Personality Trait Interaction and Mental Ill-Health over Time

\begin{tabular}{lcccc}
\hline \hline & \multicolumn{4}{c}{ Mental 11 -Health Score } \\
& Age 26 & Age 30 & Age 34 & Age 42 \\
\hline High Emotional Stability, & 0.049 & 0.082 & 0.068 & -0.013 \\
Low Conscientiousness (Age 16) & $(0.489)$ & $(0.203)$ & $(0.293)$ & $(0.850)$ \\
Low Emotional Stability, & 0.046 & 0.037 & 0.002 & $0.119^{*}$ \\
High Conscientiousness (Age 16) & $(0.434)$ & $(0.522)$ & $(0.969)$ & $(0.054)$ \\
& & & & \\
Low Emotional Stability, & $0.262^{* * *}$ & $0.230^{* * *}$ & $0.232^{* * *}$ & $0.281^{* * *}$ \\
Low Conscientiousness (Age 16) & $(0.001)$ & $(0.001)$ & $(0.001)$ & $(0.000)$ \\
& & & & \\
Agreeableness (Age 16) & 0.017 & 0.011 & -0.037 & 0.018 \\
& $(0.594)$ & $(0.699)$ & $(0.322)$ & $(0.589)$ \\
& & & \\
Extraversion (Age 16) & $-0.076^{* * *}$ & $-0.064^{* * *}$ & $-0.047^{*}$ & $-0.100^{* * *}$ \\
& $(0.003)$ & $(0.006)$ & $(0.067)$ & $(0.000)$ \\
Malaise Score (Age 16) & $0.116^{* * *}$ & $0.104^{* * *}$ & $0.100^{* * *}$ & $0.080^{* * *}$ \\
& $(0.000)$ & $(0.000)$ & $(0.000)$ & $(0.000)$ \\
Male & $-0.298^{* * *}$ & $-0.185^{* * *}$ & $-0.185^{* * *}$ & $-0.211^{* * *}$ \\
& $(0.000)$ & $(0.000)$ & $(0.000)$ & $(0.000)$ \\
\hline$N$ & 1907 & 2149 & 1983 & 1797 \\
$R^{2}$ & 0.202 & 0.153 & 0.149 & 0.134 \\
\hline \hline$p$-values in parentheses ${ }^{*} p<0.10,{ }^{* * *} p<0.05,{ }^{* * *} p<0.01$ & & \\
Source: British Cohort Study (BCS70), own calculations. & & \\
Note: We estimate OLS regressions with robust standard errors and control for mother's age, mother's \\
age squared, parental education at birth, region of birth, and child's cognitive ability at age 10.
\end{tabular}

problems at age 16 significantly increases the explained variance in the regression models. Nevertheless, the coefficients for emotional stability and the interaction term between both low emotional stability and conscientiousness stay robust. This further supports the argumentation that beside a possible underlying genetical component, behavioral variation related to personality traits matter for mental health outcomes throughout life (see also Kendler and Myers (2010)).

\subsection{Personality Change between Ages 10 and 16 and Mental Ill-Health}

To test for recursive causality at age 16 and to analyze the relevance of personality traits at younger age for mental health outcomes at adolescence and adulthood, we further look at the relation between personality at age 10 as well as a personality trait change between 10 and 16 and the incidence of mental health problems in adolescence and adulthood. A personality trait increase (decrease) is considered if the particular trait increases (decreases) by 0.5 of a standard deviation between ages 10 and 16 . Individuals who do not experience a personality trait change above or below 0.5 of a standard deviation between 
Table 7: Personality Trait Change and Mental Ill-Health over Time

\begin{tabular}{|c|c|c|c|c|c|}
\hline \multirow{3}{*}{ Emotional Stability (Age 10) } & \multicolumn{5}{|c|}{ Mental Ill-Health Score } \\
\hline & Age 16 & Age 26 & Age 30 & Age 34 & Age 42 \\
\hline & $\begin{array}{c}-0.114^{* * *} \\
(0.000)\end{array}$ & $\begin{array}{c}-0.124^{* * *} \\
(0.000)\end{array}$ & $\begin{array}{c}-0.082^{* * *} \\
(0.001)\end{array}$ & $\begin{array}{c}-0.101^{* * *} \\
(0.000)\end{array}$ & $\begin{array}{c}-0.088^{* * *} \\
(0.002)\end{array}$ \\
\hline Conscientiousness (Age 10) & $\begin{array}{c}0.006 \\
(0.839)\end{array}$ & $\begin{array}{l}-0.030 \\
(0.246)\end{array}$ & $\begin{array}{l}-0.037 \\
(0.117)\end{array}$ & $\begin{array}{c}-0.073^{* * *} \\
(0.004)\end{array}$ & $\begin{array}{c}-0.058^{* *} \\
(0.025)\end{array}$ \\
\hline Agreeableness (Age 10) & $\begin{array}{l}-0.024 \\
(0.496)\end{array}$ & $\begin{array}{c}0.008 \\
(0.783)\end{array}$ & $\begin{array}{l}-0.028 \\
(0.266)\end{array}$ & $\begin{array}{l}-0.012 \\
(0.661)\end{array}$ & $\begin{array}{l}-0.023 \\
(0.448)\end{array}$ \\
\hline Extraversion (Age 10) & $\begin{array}{c}-0.146^{* * *} \\
(0.000)\end{array}$ & $\begin{array}{c}-0.116^{* * *} \\
(0.000)\end{array}$ & $\begin{array}{c}-0.111^{* * *} \\
(0.000)\end{array}$ & $\begin{array}{c}-0.070^{* * *} \\
(0.002)\end{array}$ & $\begin{array}{c}-0.114^{* * *} \\
(0.000)\end{array}$ \\
\hline $\begin{array}{l}\text { Emotional Stability } \\
(\text { Age 16-10) }>0.5\end{array}$ & $\begin{array}{c}-0.151^{* * *} \\
(0.007)\end{array}$ & $\begin{array}{c}-0.153^{* * *} \\
(0.002)\end{array}$ & $\begin{array}{c}-0.095^{* *} \\
(0.028)\end{array}$ & $\begin{array}{c}-0.141^{* * *} \\
(0.002)\end{array}$ & $\begin{array}{l}-0.088^{*} \\
(0.087)\end{array}$ \\
\hline $\begin{array}{l}\text { Emotional Stability } \\
\text { (Age 16-10) }<-0.5\end{array}$ & $\begin{array}{c}0.254^{* * *} \\
(0.000)\end{array}$ & $\begin{array}{l}0.085^{* *} \\
(0.050)\end{array}$ & $\begin{array}{c}0.114^{* * *} \\
(0.005)\end{array}$ & $\begin{array}{c}0.140^{* * *} \\
(0.001)\end{array}$ & $\begin{array}{c}0.201^{* * *} \\
(0.000)\end{array}$ \\
\hline $\begin{array}{l}\text { Extraversion } \\
(\text { Age } 16-10)>0.5\end{array}$ & $\begin{array}{l}-0.058 \\
(0.265)\end{array}$ & $\begin{array}{c}-0.133^{* * *} \\
(0.004)\end{array}$ & $\begin{array}{l}-0.013 \\
(0.763)\end{array}$ & $\begin{array}{c}0.001 \\
(0.976)\end{array}$ & $\begin{array}{c}-0.145^{* * *} \\
(0.003)\end{array}$ \\
\hline $\begin{array}{l}\text { Extraversion } \\
(\text { Age 16-10) }<-0.5\end{array}$ & $\begin{array}{c}0.263^{* * *} \\
(0.000)\end{array}$ & $\begin{array}{c}0.147^{* * *} \\
(0.001)\end{array}$ & $\begin{array}{c}0.179^{* * *} \\
(0.000)\end{array}$ & $\begin{array}{c}0.120^{* * *} \\
(0.003)\end{array}$ & $\begin{array}{c}0.130^{* * *} \\
(0.002)\end{array}$ \\
\hline $\begin{array}{l}\text { Agreeableness } \\
(\text { Age 16-10) }>0.5\end{array}$ & $\begin{array}{c}0.027 \\
(0.637)\end{array}$ & $\begin{array}{c}0.047 \\
(0.340)\end{array}$ & $\begin{array}{c}0.011 \\
(0.802)\end{array}$ & $\begin{array}{c}0.003 \\
(0.949)\end{array}$ & $\begin{array}{c}0.067 \\
(0.206)\end{array}$ \\
\hline $\begin{array}{l}\text { Agreeableness } \\
(\text { Age 16-10) }<-0.5\end{array}$ & $\begin{array}{c}0.026 \\
(0.616)\end{array}$ & $\begin{array}{c}0.037 \\
(0.380)\end{array}$ & $\begin{array}{c}0.044 \\
(0.262)\end{array}$ & $\begin{array}{c}0.051 \\
(0.226)\end{array}$ & $\begin{array}{c}0.001 \\
(0.987)\end{array}$ \\
\hline $\begin{array}{l}\text { Conscientiousness } \\
(\text { Age 16-10) >0.5 }\end{array}$ & $\begin{array}{c}0.054 \\
(0.355)\end{array}$ & $\begin{array}{c}0.015 \\
(0.773)\end{array}$ & $\begin{array}{l}-0.010 \\
(0.816)\end{array}$ & $\begin{array}{l}-0.036 \\
(0.470)\end{array}$ & $\begin{array}{l}-0.075 \\
(0.157)\end{array}$ \\
\hline $\begin{array}{l}\text { Conscientiousness } \\
\text { (Age 16-10) }<-0.5\end{array}$ & $\begin{array}{l}0.112^{* *} \\
(0.042)\end{array}$ & $\begin{array}{c}0.116^{* * *} \\
(0.010)\end{array}$ & $\begin{array}{c}0.118^{* * *} \\
(0.005)\end{array}$ & $\begin{array}{l}0.094^{* *} \\
(0.031)\end{array}$ & $\begin{array}{c}0.033 \\
(0.470)\end{array}$ \\
\hline Male & $\begin{array}{c}-0.329^{* * *} \\
(0.000)\end{array}$ & $\begin{array}{c}-0.361^{* * *} \\
(0.000)\end{array}$ & $\begin{array}{c}-0.265^{* * *} \\
(0.000)\end{array}$ & $\begin{array}{c}-0.240^{* * *} \\
(0.000)\end{array}$ & $\begin{array}{c}-0.209^{* * *} \\
(0.000)\end{array}$ \\
\hline$N$ & 2559 & 3436 & 4200 & 3789 & 3369 \\
\hline$R^{2}$ & 0.106 & 0.097 & 0.069 & 0.068 & 0.066 \\
\hline
\end{tabular}

$p$-values in parentheses ${ }^{*} p<0.10,{ }^{* *} p<0.05,{ }^{* * *} p<0.01$

Source: British Cohort Study (BCS70), own calculations.

Note: We estimate OLS regressions with robust standard errors and control for mother's age, mother's age squared, parental education at birth, region of birth, and child's cognitive ability at age 10 . 


\section{CONCLUSION}

ages 10 and 16 are considered as the reference group. The results regarding personality trait change are provided in Table 7 .

Our results show that emotional stability at age 10 is significantly negatively related to mental ill-health at adolescence and older age and that an increase in emotional stability between 10 and 16 is significantly associated with a decrease in mental health problems, while a decrease in emotional stability between 10 and 16 is significantly related to an increase in mental health problems at ages 16, 26, 30, 34 and 42.

Table 7 further shows that conscientiousness is (borderline) negatively related to mental health issues at age 30, 34 and 42. In addition, a decrease in conscientiousness between ages 10 and 16 is significantly associated with mental health problems in adolescence and young adulthood at adolescence and adult age (except for age 42). Furthermore, we find that extraversion at age 10 is significantly negatively related to mental problems at age 16 and older age and that a decrease in extraversion between 10 and 16 is significantly associated with an increase in mental ill-health in young and adult age. Finally, we find only very limited evidence for significant gender differences in these associations. Detailed results are available upon request.

\section{Conclusion}

A increasing number of economic studies use personality traits to predict various socioeconomic outcomes and show that low emotional stability is typically negatively related to education, labor market and mental health outcomes, while conscientiousness is almost seen as a guarantor for desirable results. However, possible mechanisms behind these relations are far less explored. We contribute to the literature by analyzing the relation between low emotional stability and mental ill-health as well as the possible substitution effect of conscientiousness. On the one hand, we investigate the psychological literature and put the insights gained into an economic framework. On the other hand, we analyze the relation between personality and mental health empirically, using personality at ages 10 and 16 and mental health outcomes at ages 16, 26, 30, 34, and 42 .

Our theoretical examination shows that particularly low emotionally stable and low conscientious individuals are likely to be trapped in a self-sustained circle of mental health problems and socioeconomic disadvantage, because this group is more likely to unconsciously and repetitively use maladaptive and ineffective coping strategies also when facing influenceable challenges. Procrastination and avoidance promise short-term gains related to a reduction of negative emotion, although this behavior produces long-term costs that are likely to outweigh the short-term gains. Higher conscientiousness is likely to improve outcomes based on richer organization and time management skills as well as higher selfdiscipline.

The empirical results support our theoretical considerations. The study finds that emotional stability at age 16 significantly negatively predicts mental health problems in adolescence and adulthood. An increase in emotional stability of 1 standard deviation is related to a decrease in the mental ill-health score by between 0.08 and 0.17 of a standard deviation in adolescence and adult age which is in line with the theoretical 


\section{CONCLUSION}

considerations. The analysis further shows that the highest risk to experience mental health problems at adolescence and adulthood have individuals who score both low in emotional stability and in conscientiousness at age 16. Scoring both low in emotional stability and in conscientiousness is related to an increase in mental ill-health by between 0.25 and 0.35 of a standard deviation. Higher levels in conscientiousness at age 16 significantly mitigate the positive relation at adult age. This result is again in accordance with the economic model of neuroticism and assumed to be related to an enhanced problem solving skills, an increase of perceived control in challenging situations and less feelings of sustained stress for more conscientious individuals.

However, apart from the behavioral mechanisms described, genetic factors might be related to mental health issues at young and older age. Targeting this valid objection, the analysis reveals that the predictive power of emotional stability and conscientiousness at age 16 for mental health outcomes in adult age slightly decreases, but is still significant also after controlling for mental health issues at age 16. Nevertheless, the results suggest that individuals who experience mental health problems at age 16 are also more likely to experience these issues at adult age. An increase in the mental ill-health score by 1 is related to an increase of mental ill-health by between 0.08 and 0.11 of a standard deviation. This suggests that both a behavioral and genetic component is related to mental health problems.

Finally, the results show that emotional stability at age 10 significantly negatively predicts mental ill-health. An increase in emotional stability at age 10 is associated with a decrease in mental health problems in adolescence or adult age by between 0.08 and 0.12 of a standard deviation. Individuals who are able to increase in emotional stability between ages 10 and 16 are significantly less likely to experience mental health problems at age 16 and older age, while a decrease in emotional stability is associated with a significantly increased risk of mental health problems in adolescence or later in life. An increase in emotional stability by more than 0.5 of a standard deviation between age 10 and 16 is related to a decrease in mental ill-health at young and older age by between 0.09 and 0.15 of a standard deviation, while a decrease in emotional stability by more than 0.5 of a standard deviation between age 10 and 16 is related to a increase in mental ill-health at young and older age by between 0.09 and 0.25 of a standard deviation. These also economically significant results emphasize the importance of personality development in puberty for later life mental health outcomes.

Our theoretical considerations and empirical findings have important implications for policy-makers. There is evidence that the child's level of emotional stability is both genetically and culturally highly influenced by the family. Thus, neuroticism is considered as $50 \%$ to $60 \%$ heritable, but can also develop based on continuous exposure to anxiety and stress ${ }^{14}$ This makes it likely that the parents themselves either exhibit high neuroticism

\footnotetext{
${ }^{14}$ On the one hand, Cuijpers et al. (2010) states that "neuroticism is moderately heritable, with genetic factors determining $50 \%$ to $60 \%$ of their variance." On the other hand, Roberts (2009) argues that "continuous states of anxiety and stress can lead to neuroanatomical changes in brain structures (McEwen et al. (2006)). Stressful states likely interact with genes responsive to stress, which, in turn, affect the neuroanatomy that shapes the habitual ability of the person to respond to future environmental insults thus, a trait is born".
} 


\section{CONCLUSION}

or are less likely to be able to support their children due to serious and long-run family problems. Accordingly, higher neuroticism might be one important channel for intergenerational socioeconomic inequality that is mostly neglected so fare in economics.

Psychological studies show that school-based mental ill-health prevention programs that aim to adjust pessimistic believes and expectations and to improve the individual problem-solving ability may significantly reduce the risk of mental health problems particularly when targeted at high-risk groups (Horowitz and Garber (2006), Stice et al. (2009), Corrieri et al. (2014)). Therefore, intervention that addresses particularly low emotionally stable and low conscientious students might be a promising means to prevent or at least reduce mental health problems in adolescence and adult age. Our theoretical considerations further suggest that such interventions might also be able to boost other socioeconomic outcomes such as education or labor market outcomes among the high-risk individuals. 


\section{References}

Aldwin, C. M. and Revenson, T. A. (1987). Does Coping Help? A Reexamination of the Relation between Coping and Mental Health, Journal of Personality and Social Psychology 53(2): 337-348.

Almlund, M., Duckworth, A. L., Heckman, J. and Kautz, T. (2011). Personality Psychology and Economics, Vol. 4, Elsevier, Amsterdam, chapter 1, pp. 1-181.

Anderson, D. M., Cesur, R. and Tekin, E. (2015). Youth Depression and Future Criminal Behavior, Economic Inquiry 53(1): 294-317.

Bardasi, E. and Francesconi, M. (2004). The Effect of Non-Standard Employment on Mental Health in Britain, Social Science and Medicine 58(9): 1671-1688.

Blázquez Cuesta, M. and Budría, S. (2015). Income Deprivation and Mental Well-Being: The Role of Non-Cognitive Skills, Economics 83 Human Biology 17: 16-28.

Borghans, L., Duckworth, A. L., Heckman, J. J. and Ter Weel, B. (2008). The Economics and Psychology of Personality Traits, Journal of Human Resources 43(4): 972-1059.

Brodman, K., Erdmann, A., Lorge, I. and Broadbent, T. H. (1949). The Cornell Medical Index. An Adjunct to Medical Interview, Journal of the American Medical Association 140(6): 530-534.

Brodman, K., Erdmann, A., Lorge, I., Gershenson, C. P., Wolff, H. G. and Broadbent, T. H. (1952). The Cornell Medical Index. Health Questionnaire IV. The Recognition of Emotional Disturbances in a General Hospital, Journal of Clinical Psychology 8(3): 289293.

Broidy, L. M., Tremblay, R. E., Brame, B., Fergusson, D., Horwood, J. L., Laird, R., Moffit, T. E., Nagin, D. S., Bates, J. E., Dodge, K. A., Loeber, R., Lynam, D. R. and Gregory, P. (2003). Developmental Trajectories of Childhood Disruptive Behaviors and Adolescent Delinquency: A Six-Site, Cross-National Study, Developmental Psychology 39(2): $222-245$.

Bubonya, M., Cobb-Clark, D. A. and Wooden, M. (2016). Mental Health and Productivity at Work: Does What You Do Matter?, IZA Discussion Paper 9879.

Butler, N., Bynner, J. and University of London, Institute of Education, Centre for Longitudinal Studies (2013). 1970 British Cohort Study: Sixteen-Year Follow-Up, 1986 [computer file]. 5th Edition. Colchester, Essex: UK Data Archive [distributor], May 2013. SN: 3535 .

URL: $h t t p: / / d x . d o i . o r g / 10.5255 / U K D A-S N-3535-2$

Butler, N., Bynner, J. and University of London, Institute of Education, Centre for Longitudinal Studies (2014). 1970 British Cohort Study: Ten-Year Follow-Up, 1980 [computer file]. 5th Edition. Colchester, Essex: UK Data Archive [distributor], July 2014. SN: 3723. URL: $h t t p: / / d x$.doi.org/10.5255/UKDA-SN-3723-3

Bynner, J. and University of London, Institute of Education, Centre for Longitudinal Studies (2013). 1970 British Cohort Study: Twenty-Six-Year Follow-Up, 1996 [computer file]. 4th Edition. Colchester, Essex: UK Data Archive [distributor], May 2013. SN: 3833. URL: http://dx.doi.org/10.5255/UKDA-SN-3833-2

Caliendo, M., Cobb-Clark, D. A. and Uhlendorff, A. (2015). Locus of Control and Job Search Strategies, Review of Economics and Statistics 97(1): 88-103.

Campbell-Sills, L., Cohan, S. L. and Stein, M. B. (2006). Relationship of Resilience to Personality, Coping, and Psychiatric Symptoms in Young Adults, Behaviour Research and Therapy 44(4): 585-599. 


\section{REFERENCES}

Cardemil, E. V., Reivich, K. J., Beevers, C. G., Seligman, M. E. and James, J. (2007). The Prevention of Depressive Symptoms in Low-income, Minority Children: Two-year Follow-up, Behavior Research and Therapy 45(2): 313-327.

Carver, C. S., Scheier, M. F. and Weintraub, J. K. (1989). Assessing Coping Strategies: A Theoretically Based Approach, Journal of Personality and Social Psychology 56(2): 267283.

Cervone, D. and Pervin, L. (2014). Personality Psychology, 12 edn, Wiley, New York.

Cesur, R., Sabia, J. J. and Tekin, E. (2013). The Psychological Costs of War: Military Combat and Mental Health, Journal of Health Economics 32(1): 51-65.

Chamberlain, R., Chamberlain, G. and University of London, I. (2013). Centre for Longitudinal Studies, 1970 British Cohort Study: Birth and 22-Month Subsample, 1970-1972. $\mathrm{SN}: 2666$.

URL: http://dx.doi.org/10.5255/UKDA-SN-2666-2

Chaplin, T. M., Gillham, J. E., Reivich, K., Elkon, A. G. L., Samuels, B., Freres, D. R., Winder, B. and Seligman, M. E. P. (2006). Depression Prevention for Early Adolescent Girls: A Pilot Study of all Girls Versus Co-ed Groups, Journal of Early Adolescence 26(1): 110-126.

Cobb-Clark, D. A., Kassenboehmer, S. C. and Schurer, S. (2014). Healthy Habits: The Connection between Diet, Exercise, and Locus of Control, Journal of Economic Behavior and Organization 98: 1-28.

Compas, B. E., Connor-Smith, J. K., S. H., Thomson, A. H. and Wadsworth, M. E. (2001). Coping with Stress during Childhood and Adolescence: Progress, Problems, and Potential in Theory and Research, Psychological Bulletin 127(1): 87-127.

Connor-Smith, J. K. and Flachsbart, C. (2007). Relations between Personality and Coping: A Meta-Analysis, Journal of Personality and Social Psychology 93(6): 1080-1107.

Cornaglia, F., Crivellaro, E. and McNally, S. (2015). Mental Health and Education Decisions, Labour Economics 33: 1-12.

Cornaglia, F., Feldman, N. E. and Leigh, A. (2014). Crime and Mental Wellbeing, Journal of Human Resources 49(1): 110-140.

Corrieri, S., Heider, D., Conrad, I., Blume, A., König, H.-H. and Riedel-Heller, S. G. (2014). School-based Prevention Programs for Depression and Anxiety in Adolescence: a Systematic Review, Health Promotion International 29(3): 427-441.

Cottini, E. and Lucifora, C. (2013). Mental Health and Working Conditions in Europe, Industrial and Labor Relations Review 66(4): 958-988.

Cuijpers, P., Smit, F., Penninx, B. W., de Graaf, R., ten Have, M. and Beekman, A. T. (2010). Economic Costs of Neuroticism. A Population-Based Study, Archives of General Psychiatry 67(10): 1086-1093.

Danzer, A. M. and Danzer, N. (2016). The Long-Term Effects of the Chernobyl Catastrophe on Subjective Well-Being and Mental Health, Journal of Public Economics 135: 4760 .

Delaney, L., Fink, G. and Harmon, C. (2014). Effects of Stress on Economic DecisionMaking: Evidence from Laboratory Experiments, IZA Discussion Paper (8060).

Drydakis, N. (2015). The Effect of Unemployment on Self-Reported Health and Mental Health in Greece from 2008 to 2013: A Longitudinal Study Before and During the Financial Crisis, Social Science and Medicine 128: 43-51. 
Dustmann, C. and Fasani, F. (2016). The Effect of Local Area Crime on Mental Health, The Economic Journal 126(593): 978-1017.

Ebstrup, J. F., Eplov, L. F., Pisinger, C. and Jø rgensen, T. (2011). Association Between the Five Factor Personality Traits and Perceived Stress: Is the Effect Mediated by General Self-Efficacy?, Anxiety Stress Coping 24(4): 407-419.

Eysenck, M. J. (1988). Trait Anxiety and Stress, in S. Fisher and J. Reason (eds), Handbook of Life Stress, Cognition and Health, John Wiley and Sons, Chichester, chapter 25, pp. $467-482$.

Fletcher, J. M. (2013). The Effects of Personality Traits on Adult Labor Market Outcomes: Evidence from Siblings, Journal of Economic Behavior and Organization 89: 122-135.

Folkman, S. and Lazarus, R. S. (1985). If it Changes it Must be a Process: Study of Emotion and Coping During Three Stages of a College Examination, Journal of Personality and Social Psychology 48(1): 150-170.

Gabaix, X. and Laibson, D. (2016). Hyperbolic Discounting: Empirical Estimation, Policy Implications and Novel Interpretation. Presentation at Stirling Behavioral Science Centre Workshop on "Behavioral Science and Policy".

Gillham, J. E., Reivich, K. J., Freres, D., Lascher, M., Litzinger, S., Shatte, A. and Seligman, M. (2006). School-based Prevention of Depression and Anxiety Symptoms in Early Adolescence: A Pilot of a Parent Intervention Component, School Psychology Quarterly 21(3): 323-348.

Goldberg, L. R. (1993). The Structure of Phenotypic Personality Traits, American Psychologist 48(1): 26-34.

Golsteyn, B. H. and Schils, T. (2014). Gender Gaps in Primary School Achievement: A Decomposition into Endowments and Returns to IQ and Non-cognitive Factors, Economics of Education Review 41: 176-187.

Grant, G., Nolan, M. and Ellis, N. (1990). A Reappraisal of the Malaise Inventory, Social Psychiatry and Psychiatric Epidemiology 25(4): 170-178.

Hankin, B. L., Abramson, L. Y., Moffit, T. E., Silva, P. A., McGee, R. and Angell, K. E. (1998). Development of Depression from Preadolescents to Young Adultshood: Emerging Gender Differences in a 10-Year Longitudinal Study, Journal of Abnormal Psychology 107(1): 128-140.

Helliwell, J. F., Layard, R. and Sachs, R. (eds) (2013). World Happiness Report 2013, UN Sustainable Development Solutions Network, New York.

Horowitz, J. L. and Garber, J. (2006). The Prevention of Depressive Symptoms in Children and Adolescents: A Metaanalytic Review, Journal of Consulting and Clinical Psychology 74(3): 401-415.

Horowitz, J. L., Garber, J., Ciesla, J. A., Young, J. and Mufson, L. (2007). Prevention of Depressive Symptoms in Adolescents: A Randomized Trial of Cognitive-behavioral and Interpersonal Prevention Programs, Journal of Consulting and Clinical Psychology 75(5): 693-706.

Hudson, E. and Barrett, A. (2014). Peer Groups, Employment Status and Depressive Symptoms among Older Adults in Ireland, Journal of Population Ageing 7(1): 43-54.

Johnston, D. W., Schurer, S. and Shields, M. A. (2013). Exploring the Intergenerational Persistence of Mental Health: Evidence from Three Generations, Journal of Health Economics 32(6): 1077-1089. 
Judge, T. A. and Bono, J. E. (2001). Relationship of Core Self-Evaluations Traits-Selfesteem, Generalized Self-efficacy, Locus of Control, and Emotional Stability-with Job Satisfaction and Job Performance: A Meta-Analysis., Journal of Applied Psychology 86(1): 80-92.

Karasek, R. A. (1979). Job Demands, Job Decision Latitude, and Mental Strain: Implications for Job Redesign, Administrative Science Quarterly 24(2): 285-308.

Karasek, R. and Theorell, T. (1992). Healthy Work: Stress Productivity And The Reconstruction Of Working Life, Basis Book, United States.

Kendler, K. and Myers, J. (2010). The Genetic and Environmental Relationship between Major Depression and the Five-factor Model of Personality, Psychological Medicine 40(5): 801-806.

Layard, R., Chisholm, D., Patel, V. and Saxena, S. (2013). Mental Illness and Unhappiness, IZA Discussion Paper $\mathbf{7 6 2 0 .}$

Layard, R., Clark, A. E., Cornaglia, F., Powdthavee, N. and Vernoit, J. (2014). What Predicts a Successful Life? A Life-Course Model of Well-Being, Economic Journal 124(580): F720- F738.

Lazarus, R. S. and Folkman, S. (1984). Stress, Appraisal, and Coping, Springer, New York.

Lebel, C. and Beaulieu, C. (2011). Longitudinal Development of Human Brain Wiring Continues from Childhood into Adulthood, The Journal of Neuroscience 31(30): 1093710947.

Lindeboom, M., Portrait, F. and van den Berg, G. J. (2002). An Econometric Analysis of the Mental-Health Effects of Major Events in the Life of Elderly Individuals, Health Economics 11(6): 505-520.

Lüdtke, O., Roberts, B. W., Trautwein, U. and Nagy, G. (2011). A Random Walk Down University Avenue: Life Path, Life Events, and Personality Trait Change at the Transition to University Life, Journal of Personality and Social Psychology 101(3): 620-637.

Maclean, J. C., Xu, H., French, M. T. and Ettner, S. L. (2014). Personality Disorders and Body Weight, Economics \& Human Biology 12: 153-171.

Mani, A., Mullainathan, S., Shafir, E. and Zhao, J. (2013). Poverty Impedes Cognitive Function, Science 341(6149): 976-980.

McCrae, R. R. and John, O. P. (1992). An Introduction to the Five-Factor Model and its Applications, Journal of Personality 60(2): 175-215.

McEwen, B. S., Liston, C. and Morrison, J. H. (2006). Stress-induced Structural Plasticity in Prefrontal Cortex, Amygdala and Hippocampus, Neuropsychopharmacology 31: S 13.

McGee, R., Williams, S. and Silva, P. A. (1986). An Evaluation of the Malaise Inventory, Journal of Psychosomatic Research 30(2): 147-152.

Mendolia, S. and Walker, I. (2014). The Effect of Non-Cognitive Traits on Health Behaviours in Adolescence, Health Economics 23(9): 1146-1158.

OECD (2011). Sick on the Job? Myths and Reality about Mental Health and Work, OECD Publishing.

Penley, J. A., Tomaka, J. and Wiebe, J. S. (2002). The Association of Coping To Physical and Psychological Health Outcomes: A Meta-Analytic Review, Journal of Behavioral Medicine 25(6): 551-603. 
Persson, P. and Rossin-Slater, M. (2016). Family Ruptures, Stress, and the Mental Health of the Next Generation, American Economic Review forthcoming.

Polachek, S., Das, T. and Thamma-Apiroam, R. (2015). Micro and Macro Implications of Heterogeneity in the Production of Human Capital, Journal of Political Economy 123(6): 1410-1455.

Prevoo, T. and ter Weel, B. (2015). The Importance of Early Conscientiousness for SocioEconomic Outcomes: Evidence from the British Cohort Study, Oxford Economic Papers 67(4): 918-948.

Roberts, B. W. (2009). Back to the Future: Personality and Assessment and Personality Development, Journal of Research in Personality 43(2): 137-145.

Roberts, B. W. and Del Vecchio, W. F. (2000). The Rank-Order Consistency of Personality Traits from Childhood to Old Age: A Quantitative Review of Longitudinal Studies, Psychological Bulletin 126(1): 3-25.

Roberts, B. W., Walton, K. E. and Viechtbauer, W. (2006). Patterns of Mean-Level Change in Personality Traits Across the Life Course: A Meta-Analysis of Longitudinal Studies, Psychological Bulletin 132(1): 1-25.

Rodgers, B., Pickle, A., Power, C., Collishaw, S. and Maughan, B. (1999). Validity of the Malaise Inventory in General Population Samples, Social Psychiatry and Psychiatric Epidemiology 34(6): 333-341.

Rothbaum, F., Weisz, J. R. and Snyder, S. S. (1982). Changing the World and Changing the Self: A Two-process Model of Perceived Control, Journal of Personality and Social Psychology 42(1): 5-37.

Roy, J. and Schurer, S. (2013). Getting Stuck in the Blues: Persistence of Mental Health Problems in Australia, Health Economics 22(9): 1139-1157.

Ruhm, C. J. (2012). Understanding Overeating and Obesity., Journal of Health Economics 31(6): 781-796.

Rustichini, A., DeYoung, C. G., Anderson, J. E. and Burks, S. V. (2012). Toward the Integration of Personality Theory and Decision Theory in the Explanation of Economic and Health Behavior, IZA Discussion Paper 6750.

Rutter, M. and Madge, N. (1976). Cycles of Disadvantage, Heinemann, London.

Rutter, M., Tizard, J. and K., W. (1970). Education, Health and Behaviour, Longmans, London.

Schmitt, D. P., Realo, A., Voracek, M. and Allik, J. (2008). Why Can't a Man Be More Like a Woman? Sex Differences in Big Five Personality Traits across 55 Cultures, Journal of Personality and Social Psychology 94(1): 168-182.

Siegrist, J. (1996). Adverse Health Effects of High-Effort-Low-Reward Conditions, Journal of Occupational Health Psychology 1(1): 27-41.

Skinner, E. A., Edge, K., Altman, J. and Sherwood, H. (2003). Searching for the Structure of Coping: A Review and Critique of Category Systems for Classifying Ways of Coping, Psychological Bulletin 129(2): 216-269.

Stice, E., Shaw, H., Bohon, C., Marti, C. N. and Rohde, P. (2009). A Meta-Analytic Review of Depression Prevention Programs for Children and Adolescents: Factors that Predict Magnitude of Intervention Effects, Journal of Consulting and Clinical Psychology 77(3): 486-503. 
Straathof, B. and Weehuizen, R. (2005). Technological Change, Job Stress and Burnout, in L. Soete and B. Ter Weel (eds), The Economics of the Digital Society, Edward Elgar, Cheltenham, chapter 8, pp. 184-199.

Tefft, N. (2012). Mental Health and Employment: The Sad Story, Economics 83 Human Biology 10(3): 242-255.

UK Data Service (2016). Background to the Malaise Inventory: Measure Levels of Psychological Distress or Depression.

URL: https://www.ukdataservice.ac.uk/teaching-resources/malaise/background

University of London. Institute of Education. Centre for Longitudinal Studies (2012). 1970 British Cohort Study: Forty-Two-Year Follow-Up, 2012 [computer file]. Colchester, Essex: UK Data Archive [distributor], March 2014. SN: 7473.

URL: http://dx.doi.org/10.5255/UKDA-SN-7473-1

University of London, Institute of Education, Centre for Longitudinal Studies (2013a). 1970 British Cohort Study: Thirty-Four-Year Follow-Up, 2004-2005 [computer file]. 3rd Edition. Colchester, Essex: UK Data Archive [distributor], May 2013. SN: 5585.

URL: $h t t p: / / d x . d o i . o r g / 10.5255 / U K D A-S N-5585-2$

University of London, Institute of Education, Centre for Longitudinal Studies (2013b). 1970 British Cohort Study: Twenty-Nine-Year Follow-Up, 1999-2000 [computer file]. 3rd Edition. Joint Centre for Longitudinal Research, [original data producer(s)]. Colchester, Essex: UK Data Archive [distributor], May 2013. SN: 5558.

URL: http://dx.doi.org/10.5255/UKDA-SN-5558-2

Ursin, H. and Eriksen, H. R. (2004). The Cognitive Activation Theory of Stress, Psychoneuroendocrinology 29(5): 567-92.

Young, J. F., Mufson, L. and Davies, M. (2006). Efficacy of Interpersonal PsychotherapyAdolescent Skills Training: An Indicated Preventive Intervention for Depression, Journal of Child Psychology and Psychiatry 47(12): 1254-1262. 
A DATA

\section{A Data}

Table 8: Number of Observations by Wave and Variables Used

\begin{tabular}{|c|c|c|c|}
\hline $\begin{array}{l}\text { Wave, } \\
\text { Year }\end{array}$ & $\mathbf{N}$ & Dataset & Variables \\
\hline $\begin{array}{l}\text { Wave } \\
1,1970\end{array}$ & 17,196 & $\begin{array}{l}\text { SN2666: Chamberlain et al. } \\
(2013)\end{array}$ & $\begin{array}{l}\text { Mother's age at birth, region of } \\
\text { birth, child's sex, parental so- } \\
\text { cioeconomic status at birth. }\end{array}$ \\
\hline $\begin{array}{l}\text { Wave } \\
2,1975\end{array}$ & 13,135 & not used & - \\
\hline $\begin{array}{l}\text { Wave } \\
3,1980\end{array}$ & 14,875 & SN3723: Butler et al. 2014 & $\begin{array}{l}\text { Test scores and personality } \\
\text { traits at age } 10 .\end{array}$ \\
\hline $\begin{array}{l}\text { Wave } \\
4,1986\end{array}$ & 11,615 & SN3535: Butler et al. 2013 & $\begin{array}{l}\text { Personality traits as well as } \\
\text { mental ill-health at age } 16 \text {. }\end{array}$ \\
\hline $\begin{array}{l}\text { Wave } \\
5,1996\end{array}$ & 9,003 & $\begin{array}{l}\text { SN3833: Bynner and University } \\
\begin{array}{|l|}\text { of London, Institute of Edu- } \\
\text { cation, Centre for Longitudinal } \\
\text { Studies (2013) }\end{array}\end{array}$ & Mental ill-health at age 26. \\
\hline $\begin{array}{l}\text { Wave } \\
6,2000\end{array}$ & 11,261 & $\begin{array}{l}\text { SN5558: University of London, } \\
\text { Institute of Education, Cen- } \\
\text { tre for Longitudinal Studies } \\
(2013 \mathrm{~b}) \\
\end{array}$ & Mental ill-health at age 30. \\
\hline $\begin{array}{l}\text { Wave } \\
7,2004\end{array}$ & 9,665 & $\begin{array}{l}\text { SN5585: University of London, } \\
\begin{array}{|l}\text { Institute of Education, Cen- } \\
\text { tre for Longitudinal Studies } \\
(2013 \mathrm{a})\end{array} \\
\end{array}$ & Mental ill-health at age 34 . \\
\hline $\begin{array}{l}\text { Wave } \\
8,2008\end{array}$ & 8,874 & not used & - \\
\hline $\begin{array}{l}\text { Wave } \\
9,2012\end{array}$ & 9,841 & $\begin{array}{l}\text { SN7473: University of London. } \\
\text { Institute of Education. Centre } \\
\text { for Longitudinal Studies (2012) }\end{array}$ & Mental ill-health at age 42 . \\
\hline
\end{tabular}




\section{A DATA}

Table 9: Malaise Items

\begin{tabular}{|c|c|c|c|c|c|c|}
\hline Question & Age 16 & Age 26 & Age 30 & Age 34 & Age 38 & Age 42 \\
\hline $\begin{array}{l}\text { 1. Do you often have back- } \\
\text { ache? }\end{array}$ & $\sqrt{ }$ & $\sqrt{ }$ & $\sqrt{ }$ & $\otimes$ & $\otimes$ & $\otimes$ \\
\hline $\begin{array}{l}\text { 2. Do you feel tired most } \\
\text { of the time? }\end{array}$ & $\sqrt{ }$ & $\sqrt{ }$ & $\sqrt{ }$ & $\sqrt{ }$ & $\otimes$ & $\sqrt{ }$ \\
\hline $\begin{array}{l}\text { 3. Do you often feel de- } \\
\text { pressed? }\end{array}$ & $\sqrt{ }$ & $\sqrt{ }$ & $\sqrt{ }$ & $\sqrt{ }$ & $\otimes$ & $\sqrt{ }$ \\
\hline $\begin{array}{l}\text { 4. Do you often have bad } \\
\text { headaches? }\end{array}$ & $\sqrt{ }$ & $\sqrt{ }$ & $\sqrt{ }$ & $\otimes$ & $\otimes$ & $\otimes$ \\
\hline $\begin{array}{l}\text { 5. Do you often get wor- } \\
\text { ried about things? }\end{array}$ & $\sqrt{ }$ & $\sqrt{ }$ & $\sqrt{ }$ & $\sqrt{ }$ & $\otimes$ & $\sqrt{ }$ \\
\hline $\begin{array}{l}\text { 6. Do you usually have great } \\
\text { difficulty in falling or staying } \\
\text { asleep? }\end{array}$ & $\sqrt{ }$ & $\sqrt{ }$ & $\sqrt{ }$ & $\otimes$ & $\otimes$ & $\otimes$ \\
\hline $\begin{array}{l}\text { 7. Do you usually wake un- } \\
\text { necessarily early in the morn- } \\
\text { ing? }\end{array}$ & $\sqrt{ }$ & $\sqrt{ }$ & $\sqrt{ }$ & $\otimes$ & $\otimes$ & $\otimes$ \\
\hline $\begin{array}{l}\text { 8. Do you wear yourself out } \\
\text { worrying about your health? }\end{array}$ & $\sqrt{ }$ & $\sqrt{ }$ & $\sqrt{ }$ & $\otimes$ & $\otimes$ & $\otimes$ \\
\hline $\begin{array}{l}\text { 9. Do you often get into } \\
\text { violent rage? }\end{array}$ & $\sqrt{ }$ & $\sqrt{ }$ & $\sqrt{ }$ & $\sqrt{ }$ & $\otimes$ & $\sqrt{ }$ \\
\hline $\begin{array}{l}\text { 10. Do people annoy and irri- } \\
\text { tate you? }\end{array}$ & $\sqrt{ }$ & $\sqrt{ }$ & $\sqrt{ }$ & $\otimes$ & $\otimes$ & $\otimes$ \\
\hline $\begin{array}{l}\text { 11. Have you at times had a } \\
\text { twitching of the face, head or } \\
\text { shoulders? }\end{array}$ & $\sqrt{ }$ & $\sqrt{ }$ & $\sqrt{ }$ & $\otimes$ & $\otimes$ & $\otimes$ \\
\hline $\begin{array}{l}\text { 12. Do you suddenly be- } \\
\text { come scared for no good } \\
\text { reason? }\end{array}$ & $\sqrt{ }$ & $\sqrt{ }$ & $\sqrt{ }$ & $\sqrt{ }$ & $\otimes$ & $\sqrt{ }$ \\
\hline $\begin{array}{l}\text { 13. Are you scared to be alone } \\
\text { when there are no friends } \\
\text { near you? }\end{array}$ & $\sqrt{ }$ & $\sqrt{ }$ & $\sqrt{ }$ & $\otimes$ & $\otimes$ & $\otimes$ \\
\hline $\begin{array}{l}\text { 14. Are you easily upset } \\
\text { or irritated? }\end{array}$ & $\sqrt{ }$ & $\sqrt{ }$ & $\sqrt{ }$ & $\sqrt{ }$ & $\otimes$ & $\sqrt{ }$ \\
\hline $\begin{array}{l}\text { 15. Are you frightened of go- } \\
\text { ing out alone or of meeting } \\
\text { people? }\end{array}$ & $\sqrt{ }$ & $\sqrt{ }$ & $\sqrt{ }$ & $\otimes$ & $\otimes$ & $\otimes$ \\
\hline $\begin{array}{l}\text { 16. Are constantly keyed } \\
\text { up and jittery? }\end{array}$ & $\sqrt{ }$ & $\sqrt{ }$ & $\sqrt{ }$ & $\sqrt{ }$ & $\otimes$ & $\sqrt{ }$ \\
\hline $\begin{array}{l}\text { 17. Do you suffer from indi- } \\
\text { gestion? }\end{array}$ & $\sqrt{ }$ & $\sqrt{ }$ & $\sqrt{ }$ & $\otimes$ & $\otimes$ & $\otimes$ \\
\hline $\begin{array}{l}\text { 18. Do you suffer from an up- } \\
\text { set stomach? }\end{array}$ & $\sqrt{ }$ & $\sqrt{ }$ & $\sqrt{ }$ & $\otimes$ & $\otimes$ & $\otimes$ \\
\hline 19. Is your appetite poor? & $\sqrt{ }$ & $\sqrt{ }$ & $\sqrt{ }$ & $\otimes$ & $\otimes$ & $\otimes$ \\
\hline $\begin{array}{l}\text { 20. Does every little thing } \\
\text { get on your nerves and } \\
\text { wear you out? }\end{array}$ & $\sqrt{ }$ & $\sqrt{ }$ & $\sqrt{ }$ & $\sqrt{ }$ & $\otimes$ & $\sqrt{ }$ \\
\hline $\begin{array}{l}\text { 21. Does your heart often } \\
\text { race like mad? }\end{array}$ & $\sqrt{ }$ & $\sqrt{ }$ & $\sqrt{ }$ & $\sqrt{ }$ & $\otimes$ & $\sqrt{ }$ \\
\hline $\begin{array}{l}\text { 22. Do you often have bad } \\
\text { pain in eyes? }\end{array}$ & $\sqrt{ }$ & $\sqrt{ }$ & $\sqrt{ }$ & $\otimes$ & $\otimes$ & $\otimes$ \\
\hline $\begin{array}{l}\text { 23. Are you troubled with } \\
\text { rheumatism or fibrosis? }\end{array}$ & $\otimes$ & $\sqrt{ }$ & $\sqrt{ }$ & $\otimes$ & $\otimes$ & $\otimes$ \\
\hline $\begin{array}{l}24 \text {. Have you ever had a ner- } \\
\text { vous breakdown? }\end{array}$ & $\otimes$ & $\sqrt{ }$ & $\sqrt{ }$ & $\otimes$ & $\otimes$ & $\otimes$ \\
\hline $\begin{array}{l}\text { Number of malaise items } \\
\text { Measurement scale }\end{array}$ & 22 & 24 & 24 & 9 & 0 & 9 \\
\hline per malaise item & $\begin{array}{l}\text { 3-point: } 0,1, \\
2\end{array}$ & 2-point: 0,1 & 2-point: 0,1 & 2-point: 0,1 & - & 2-point: 0,1 \\
\hline $\begin{array}{l}\text { Measurement scale } \\
\text { per malaise score }\end{array}$ & $0-44$ & $0-24$ & $0-24$ & $0-9$ & - & $0-9$ \\
\hline Threshold for depression & 15 & 8 & 8 & 4 & - & 4 \\
\hline $\begin{array}{l}\text { Unrestricted number } \\
\text { of valid observations }\end{array}$ & 4,673 & 8,044 & 10,251 & 8,866 & 0 & 7,935 \\
\hline
\end{tabular}

Source: BCS70. Own calculations.

Note: The 9 items that are marked bold are used in our analysis. 


\section{A DATA}

Table 10: Correlation between Personality Traits and Mental Health Outcomes

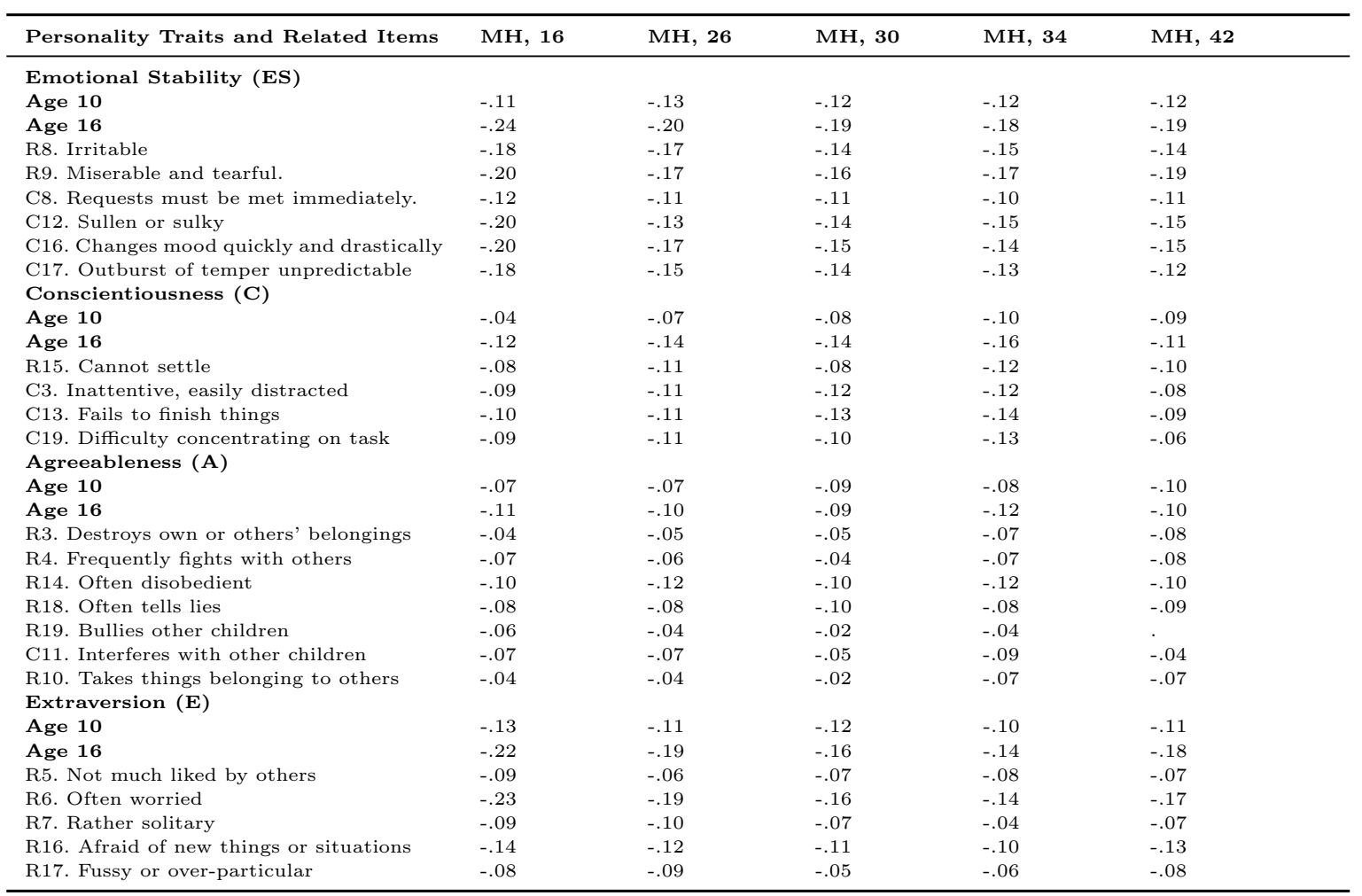

Source: BCS70, own calculations. Items are stated in orginal terms, but reversly used in the analysis.

Note: Correlation coefficients reported are significant at the 5 percent level or higher.

$\mathrm{MH}=$ Mental Health Problems at ages $16(\mathrm{n}=2559), 26(\mathrm{n}=3436), 30(\mathrm{n}=4200), 34(\mathrm{n}=3789)$, and $42(\mathrm{n}=3369)$.

Table 11: Cognitive Ability Measures at Age 10

\begin{tabular}{|c|c|}
\hline Educational Test & Components \\
\hline British Abilities Scale (BAS) & $\begin{array}{l}\text { Self-completion; Non-verbal: Recall of digits ( } 34 \text { items), ma- } \\
\text { trices ( } 28 \text { items); Verbal: Word definitions ( } 37 \text { items), word } \\
\text { similarities ( } 42 \text { items). }\end{array}$ \\
\hline Shortened Edinburgh Reading Test (ERT) & Self-completion; 64 items ( 67 in documentation). \\
\hline Friendly Maths Test (FMT) & 72 multiple choice questions. \\
\hline Pictorial Language Comprehension Test (PLCT) & $\begin{array}{l}\text { Vocabulary items, sequencing items, sentence comprehen- } \\
\text { sion items; } 100 \text { items. }\end{array}$ \\
\hline Diagnostic Test & Reading (108 items) and spelling test (50 items). \\
\hline
\end{tabular}




\section{B Descriptives Working vs. Unrestricted Sample}

Table 12: Descriptives Age 16 : Working, Unrestricted Sample

\begin{tabular}{|c|c|c|c|c|c|c|c|c|c|c|}
\hline Variable Names & $\mathrm{N}$ & mean & sd & $\min$ & $\max$ & $\mathrm{N}$ & mean & $\mathrm{sd}$ & $\min$ & $\max$ \\
\hline Malaise Score (Age 16) & 2559 & -0.03 & 0.98 & -1.51 & 4.15 & 4673 & 0.00 & 1.00 & -1.51 & 4.86 \\
\hline Emotional Stability (ES, 10) & 2559 & 0.12 & 0.90 & -3.23 & 1.26 & 11796 & 0.00 & 1.00 & -3.51 & 1.34 \\
\hline Conscientiousness $(\mathrm{C}, 10)$ & 2559 & 0.19 & 0.87 & -3.31 & 1.20 & 11796 & 0.00 & 1.00 & -3.35 & 1.20 \\
\hline Agreeableness (A, 10) & 2559 & 0.14 & 0.79 & -5.79 & 1.27 & 11796 & 0.00 & 1.00 & -6.48 & 1.38 \\
\hline Extraversion $(\mathrm{E}, 10)$ & 2559 & 0.01 & 1.00 & -3.27 & 1.47 & 11796 & -0.00 & 1.00 & -3.62 & 1.47 \\
\hline Emotional Stability (ES, 16) & 2559 & 0.08 & 0.92 & -4.00 & 0.85 & 7132 & -0.00 & 1.00 & -4.00 & 0.85 \\
\hline Conscientiousness (C, 16) & 2559 & 0.14 & 0.88 & -4.65 & 0.72 & 7132 & -0.00 & 1.00 & -4.65 & 0.72 \\
\hline Agreeableness (A, 16) & 2559 & 0.17 & 0.77 & -6.54 & 0.53 & 7132 & 0.00 & 1.00 & -6.61 & 0.53 \\
\hline Extraversion $(\mathrm{E}, 16)$ & 2559 & 0.00 & 0.98 & -4.82 & 0.96 & 7132 & 0.00 & 1.00 & -4.82 & 0.96 \\
\hline High ES, High C (16) & 2559 & 0.55 & 0.50 & 0.00 & 1.00 & 7132 & 0.49 & 0.50 & 0.00 & 1.00 \\
\hline High ES, Low C (16) & 2559 & 0.12 & 0.32 & 0.00 & 1.00 & 7132 & 0.14 & 0.35 & 0.00 & 1.00 \\
\hline Low ES, High C (16) & 2559 & 0.16 & 0.37 & 0.00 & 1.00 & 7132 & 0.16 & 0.37 & 0.00 & 1.00 \\
\hline Low ES, Low C (16) & 2559 & 0.17 & 0.38 & 0.00 & 1.00 & 7132 & 0.21 & 0.41 & 0.00 & 1.00 \\
\hline Cog. Ability z (10) & 2559 & 0.39 & 0.88 & -3.21 & 2.44 & 11598 & -0.00 & 1.00 & -4.42 & 2.49 \\
\hline Social Class I or II (0) & 2559 & 0.23 & 0.42 & 0.00 & 1.00 & 17164 & 0.18 & 0.39 & 0.00 & 1.00 \\
\hline Region & 2559 & 5.71 & 2.70 & 1.00 & 10.00 & 17185 & 5.89 & 2.70 & 1.00 & 11.00 \\
\hline Age Mother (0) & 2559 & 23.02 & 3.98 & 14.00 & 42.00 & 17067 & 22.15 & 4.03 & 12.00 & 47.00 \\
\hline Male & 2559 & 0.41 & 0.49 & 0.00 & 1.00 & 17185 & 0.52 & 0.50 & 0.00 & 1.00 \\
\hline
\end{tabular}

Source: British Cohort Study (BCS70), own calculations.

Table 13: Descriptives Age 26 : Working, Unrestricted Sample

\begin{tabular}{lcccccccccc}
\hline \hline \multicolumn{1}{c}{ Variable Names } & $\mathrm{N}$ & mean & $\mathrm{sd}$ & $\mathrm{min}$ & $\mathrm{max}$ & $\mathrm{N}$ & $\mathrm{mean}$ & $\mathrm{sd}$ & $\min$ & $\max$ \\
\hline Malaise Score (Age 26) & 3436 & -0.05 & 0.96 & -1.00 & 4.07 & 8044 & -0.00 & 1.00 & -1.00 & 4.07 \\
Emotional Stability (ES, 10) & 3436 & 0.13 & 0.89 & -3.37 & 1.26 & 11796 & 0.00 & 1.00 & -3.51 & 1.34 \\
Conscientiousness (C, 10) & 3436 & 0.16 & 0.89 & -3.11 & 1.20 & 11796 & 0.00 & 1.00 & -3.35 & 1.20 \\
Agreeableness (A, 10) & 3436 & 0.12 & 0.82 & -5.98 & 1.27 & 11796 & 0.00 & 1.00 & -6.48 & 1.38 \\
Extraversion (E, 10) & 3436 & 0.01 & 0.98 & -3.55 & 1.47 & 11796 & -0.00 & 1.00 & -3.62 & 1.47 \\
Emotional Stability (ES, 16) & 3436 & 0.08 & 0.94 & -4.00 & 0.85 & 7132 & -0.00 & 1.00 & -4.00 & 0.85 \\
Conscientiousness (C, 16) & 3436 & 0.12 & 0.89 & -4.65 & 0.72 & 7132 & -0.00 & 1.00 & -4.65 & 0.72 \\
Agreeableness (A, 16) & 3436 & 0.11 & 0.89 & -6.54 & 0.53 & 7132 & 0.00 & 1.00 & -6.61 & 0.53 \\
Extraversion (E, 16) & 3436 & 0.02 & 0.97 & -4.82 & 0.96 & 7132 & 0.00 & 1.00 & -4.82 & 0.96 \\
High ES, High C (16) & 3436 & 0.54 & 0.50 & 0.00 & 1.00 & 7132 & 0.49 & 0.50 & 0.00 & 1.00 \\
High ES, Low C (16) & 3436 & 0.13 & 0.34 & 0.00 & 1.00 & 7132 & 0.14 & 0.35 & 0.00 & 1.00 \\
Low ES, High C (16) & 3436 & 0.16 & 0.37 & 0.00 & 1.00 & 7132 & 0.16 & 0.37 & 0.00 & 1.00 \\
Low ES, Low C (16) & 3436 & 0.17 & 0.38 & 0.00 & 1.00 & 7132 & 0.21 & 0.41 & 0.00 & 1.00 \\
Cog. Ability z (10) & 3436 & 0.32 & 0.88 & -3.21 & 2.44 & 11598 & -0.00 & 1.00 & -4.42 & 2.49 \\
Social Class I or II (0) & 3436 & 0.21 & 0.41 & 0.00 & 1.00 & 17164 & 0.18 & 0.39 & 0.00 & 1.00 \\
Region & 3436 & 5.61 & 2.69 & 1.00 & 10.00 & 17185 & 5.89 & 2.70 & 1.00 & 11.00 \\
Age Mother (0) & 3436 & 22.85 & 3.96 & 15.00 & 46.00 & 17067 & 22.15 & 4.03 & 12.00 & 47.00 \\
Male & 3436 & 0.43 & 0.49 & 0.00 & 1.00 & 17185 & 0.52 & 0.50 & 0.00 & 1.00 \\
\hline \hline
\end{tabular}

Source: British Cohort Study (BCS70), own calculations. 
Table 14: Descriptives Age 30 : Working, Unrestricted Sample

\begin{tabular}{|c|c|c|c|c|c|c|c|c|c|c|}
\hline Variable Names & $\mathrm{N}$ & mean & $\mathrm{sd}$ & $\min$ & $\max$ & $\mathrm{N}$ & mean & $\mathrm{sd}$ & $\min$ & $\max$ \\
\hline Malaise Score (Age 30) & 4200 & -0.05 & 0.96 & -0.88 & 4.24 & 10251 & -0.00 & 1.00 & -0.88 & 4.24 \\
\hline Emotional Stability (ES, 10) & 4200 & 0.10 & 0.92 & -3.45 & 1.28 & 11796 & 0.00 & 1.00 & -3.51 & 1.34 \\
\hline Conscientiousness $(\mathrm{C}, 10)$ & 4200 & 0.11 & 0.92 & -3.31 & 1.20 & 11796 & 0.00 & 1.00 & -3.35 & 1.20 \\
\hline Agreeableness (A, 10) & 4200 & 0.08 & 0.87 & -6.37 & 1.27 & 11796 & 0.00 & 1.00 & -6.48 & 1.38 \\
\hline Extraversion $(\mathrm{E}, 10)$ & 4200 & 0.01 & 0.98 & -3.61 & 1.47 & 11796 & -0.00 & 1.00 & -3.62 & 1.47 \\
\hline Emotional Stability (ES, 16) & 4200 & 0.06 & 0.95 & -4.00 & 0.85 & 7132 & -0.00 & 1.00 & -4.00 & 0.85 \\
\hline Conscientiousness $(\mathrm{C}, 16)$ & 4200 & 0.06 & 0.93 & -4.65 & 0.72 & 7132 & -0.00 & 1.00 & -4.65 & 0.72 \\
\hline Agreeableness (A, 16) & 4200 & 0.06 & 0.93 & -6.61 & 0.53 & 7132 & 0.00 & 1.00 & -6.61 & 0.53 \\
\hline Extraversion $(\mathrm{E}, 16)$ & 4200 & 0.03 & 0.96 & -4.82 & 0.96 & 7132 & 0.00 & 1.00 & -4.82 & 0.96 \\
\hline High ES, High C (16) & 4200 & 0.51 & 0.50 & 0.00 & 1.00 & 7132 & 0.49 & 0.50 & 0.00 & 1.00 \\
\hline High ES, Low C (16) & 4200 & 0.14 & 0.35 & 0.00 & 1.00 & 7132 & 0.14 & 0.35 & 0.00 & 1.00 \\
\hline Low ES, High C (16) & 4200 & 0.16 & 0.36 & 0.00 & 1.00 & 7132 & 0.16 & 0.37 & 0.00 & 1.00 \\
\hline Low ES, Low C (16) & 4200 & 0.19 & 0.39 & 0.00 & 1.00 & 7132 & 0.21 & 0.41 & 0.00 & 1.00 \\
\hline Cog. Ability z (10) & 4200 & 0.23 & 0.92 & -3.21 & 2.44 & 11598 & -0.00 & 1.00 & -4.42 & 2.49 \\
\hline Social Class I or II (0) & 4200 & 0.20 & 0.40 & 0.00 & 1.00 & 17164 & 0.18 & 0.39 & 0.00 & 1.00 \\
\hline Region & 4200 & 5.66 & 2.70 & 1.00 & 10.00 & 17185 & 5.89 & 2.70 & 1.00 & 11.00 \\
\hline Age Mother (0) & 4200 & 22.65 & 3.95 & 14.00 & 46.00 & 17067 & 22.15 & 4.03 & 12.00 & 47.00 \\
\hline Male & 4200 & 0.46 & 0.50 & 0.00 & 1.00 & 17185 & 0.52 & 0.50 & 0.00 & 1.00 \\
\hline
\end{tabular}

Source: British Cohort Study (BCS70), own calculations.

Table 15: Descriptives Age 34 : Working, Unrestricted Sample

\begin{tabular}{|c|c|c|c|c|c|c|c|c|c|c|}
\hline Variable Names & $\mathrm{N}$ & mean & sd & $\min$ & $\max$ & $\mathrm{N}$ & mean & sd & $\min$ & $\max$ \\
\hline Malaise Score (Age 34) & 3789 & -0.04 & 0.98 & -0.88 & 3.87 & 8866 & 0.00 & 1.00 & -0.88 & 3.87 \\
\hline Emotional Stability (ES, 10) & 3789 & 0.11 & 0.91 & -3.45 & 1.26 & 11796 & 0.00 & 1.00 & -3.51 & 1.34 \\
\hline Conscientiousness $(\mathrm{C}, 10)$ & 3789 & 0.12 & 0.92 & -3.31 & 1.20 & 11796 & 0.00 & 1.00 & -3.35 & 1.20 \\
\hline Agreeableness (A, 10) & 3789 & 0.10 & 0.84 & -6.37 & 1.26 & 11796 & 0.00 & 1.00 & -6.48 & 1.38 \\
\hline Extraversion $(\mathrm{E}, 10)$ & 3789 & 0.02 & 0.99 & -3.61 & 1.47 & 11796 & -0.00 & 1.00 & -3.62 & 1.47 \\
\hline Emotional Stability (ES, 16) & 3789 & 0.07 & 0.94 & -4.00 & 0.85 & 7132 & -0.00 & 1.00 & -4.00 & 0.85 \\
\hline Conscientiousness (C, 16) & 3789 & 0.08 & 0.92 & -4.65 & 0.72 & 7132 & -0.00 & 1.00 & -4.65 & 0.72 \\
\hline Agreeableness (A, 16) & 3789 & 0.08 & 0.90 & -6.54 & 0.53 & 7132 & 0.00 & 1.00 & -6.61 & 0.53 \\
\hline Extraversion (E, 16) & 3789 & 0.03 & 0.97 & -4.82 & 0.96 & 7132 & 0.00 & 1.00 & -4.82 & 0.96 \\
\hline High ES, High C (16) & 3789 & 0.52 & 0.50 & 0.00 & 1.00 & 7132 & 0.49 & 0.50 & 0.00 & 1.00 \\
\hline High ES, Low C (16) & 3789 & 0.14 & 0.35 & 0.00 & 1.00 & 7132 & 0.14 & 0.35 & 0.00 & 1.00 \\
\hline Low ES, High C (16) & 3789 & 0.16 & 0.36 & 0.00 & 1.00 & 7132 & 0.16 & 0.37 & 0.00 & 1.00 \\
\hline Low ES, Low C (16) & 3789 & 0.18 & 0.39 & 0.00 & 1.00 & 7132 & 0.21 & 0.41 & 0.00 & 1.00 \\
\hline Cog. Ability z (10) & 3789 & 0.26 & 0.91 & -3.53 & 2.44 & 11598 & -0.00 & 1.00 & -4.42 & 2.49 \\
\hline Social Class I or II (0) & 3789 & 0.21 & 0.41 & 0.00 & 1.00 & 17164 & 0.18 & 0.39 & 0.00 & 1.00 \\
\hline Region & 3789 & 5.65 & 2.69 & 1.00 & 10.00 & 17185 & 5.89 & 2.70 & 1.00 & 11.00 \\
\hline Age Mother (0) & 3789 & 22.76 & 3.93 & 14.00 & 46.00 & 17067 & 22.15 & 4.03 & 12.00 & 47.00 \\
\hline Male & 3789 & 0.45 & 0.50 & 0.00 & 1.00 & 17185 & 0.52 & 0.50 & 0.00 & 1.00 \\
\hline
\end{tabular}


B DESCRIPTIVES WORKING VS. UNRESTRICTED SAMPLE

Table 16: Descriptives Age 42 : Working, Unrestricted Sample

\begin{tabular}{|c|c|c|c|c|c|c|c|c|c|c|}
\hline Variable Names & $\mathrm{N}$ & mean & sd & $\min$ & $\max$ & $\mathrm{N}$ & mean & sd & $\min$ & $\max$ \\
\hline Malaise Score (Age 42) & 3369 & -0.04 & 0.96 & -0.93 & 3.57 & 7935 & 0.00 & 1.00 & -0.93 & 3.57 \\
\hline Emotional Stability (ES, 10) & 3369 & 0.11 & 0.91 & -3.45 & 1.26 & 11796 & 0.00 & 1.00 & -3.51 & 1.34 \\
\hline Conscientiousness $(\mathrm{C}, 10)$ & 3369 & 0.14 & 0.91 & -3.31 & 1.20 & 11796 & 0.00 & 1.00 & -3.35 & 1.20 \\
\hline Agreeableness $(\mathrm{A}, 10)$ & 3369 & 0.12 & 0.83 & -6.37 & 1.26 & 11796 & 0.00 & 1.00 & -6.48 & 1.38 \\
\hline Extraversion (E, 10) & 3369 & 0.02 & 0.99 & -3.61 & 1.47 & 11796 & -0.00 & 1.00 & -3.62 & 1.47 \\
\hline Emotional Stability (ES, 16) & 3369 & 0.06 & 0.95 & -4.00 & 0.85 & 7132 & -0.00 & 1.00 & -4.00 & 0.85 \\
\hline Conscientiousness (C, 16) & 3369 & 0.10 & 0.90 & -4.65 & 0.72 & 7132 & -0.00 & 1.00 & -4.65 & 0.72 \\
\hline Agreeableness (A, 16) & 3369 & 0.09 & 0.90 & -6.54 & 0.53 & 7132 & 0.00 & 1.00 & -6.61 & 0.53 \\
\hline Extraversion (E, 16) & 3369 & 0.02 & 0.96 & -4.82 & 0.96 & 7132 & 0.00 & 1.00 & -4.82 & 0.96 \\
\hline High ES, High C (16) & 3369 & 0.53 & 0.50 & 0.00 & 1.00 & 7132 & 0.49 & 0.50 & 0.00 & 1.00 \\
\hline High ES, Low C (16) & 3369 & 0.13 & 0.34 & 0.00 & 1.00 & 7132 & 0.14 & 0.35 & 0.00 & 1.00 \\
\hline Low ES, High C (16) & 3369 & 0.16 & 0.37 & 0.00 & 1.00 & 7132 & 0.16 & 0.37 & 0.00 & 1.00 \\
\hline Low ES, Low C (16) & 3369 & 0.18 & 0.38 & 0.00 & 1.00 & 7132 & 0.21 & 0.41 & 0.00 & 1.00 \\
\hline Cog. Ability z (10) & 3369 & 0.28 & 0.90 & -3.74 & 2.44 & 11598 & -0.00 & 1.00 & -4.42 & 2.49 \\
\hline Social Class I or II (0) & 3369 & 0.22 & 0.41 & 0.00 & 1.00 & 17164 & 0.18 & 0.39 & 0.00 & 1.00 \\
\hline Region & 3369 & 5.54 & 2.66 & 1.00 & 10.00 & 17185 & 5.89 & 2.70 & 1.00 & 11.00 \\
\hline Age Mother (0) & 3369 & 22.77 & 3.94 & 14.00 & 46.00 & 17067 & 22.15 & 4.03 & 12.00 & 47.00 \\
\hline Male & 3369 & 0.44 & 0.50 & 0.00 & 1.00 & 17185 & 0.52 & 0.50 & 0.00 & 1.00 \\
\hline
\end{tabular}

Source: British Cohort Study (BCS70), own calculations. 